\title{
Review \\ Current and Future Applications of Artificial Intelligence in Coronary Artery Disease
}

\author{
Nitesh Gautam ${ }^{1}$, Prachi Saluja ${ }^{1}$, Abdallah Malkawi ${ }^{2}$, Mark G. Rabbat ${ }^{3}$, Mouaz H. Al-Mallah ${ }^{4}$ (D), \\ Gianluca Pontone ${ }^{5}$ (D), Yiye Zhang ${ }^{6}$, Benjamin C. Lee ${ }^{7}$ (D) and Subhi J. Al'Aref ${ }^{2 * *(D)}$
}

1 Department of Internal Medicine, University of Arkansas for Medical Sciences, Little Rock, AR 72205, USA; ngautam@uams.edu (N.G.); psaluja@uams.edu (P.S.)

2 Department of Medicine, Division of Cardiology, University of Arkansas for Medical Sciences, Little Rock, AR 72205, USA; amalkawi@uams.edu

3 Division of Cardiology, Loyola University Medical Center, Chicago, IL 60153, USA; mrabbat@lumc.edu

4 Houston Methodist DeBakey Heart \& Vascular Center, Houston, TX 77030, USA; mouaz74@gmail.com

5 Centro Cardiologico Monzino IRCCS, 20138 Milan, Italy; gianluca.pontone@ccfm.it

6 Department of Population Health Sciences, Weill Cornell Medicine, New York, NY 10021, USA; yiz2014@med.cornell.edu

7 Department of Radiology, Dalio Institute of Cardiovascular Imaging, New York-Presbyterian Hospital and Weill Cornell Medicine, New York, NY 10021, USA; bcl2004@med.cornell.edu

* Correspondence: sjalaref@uams.edu

\section{check for}

updates

Citation: Gautam, N.; Saluja, P.;

Malkawi, A.; Rabbat, M.G.;

Al-Mallah, M.H.; Pontone, G.; Zhang,

Y.; Lee, B.C.; $\mathrm{Al}^{\prime}$ Aref, S.J. Current and

Future Applications of Artificial

Intelligence in Coronary Artery

Disease. Healthcare 2022, 10, 232.

https://doi.org/10.3390/

healthcare10020232

Academic Editor: Mahmudur

Rahman

Received: 14 December 2021

Accepted: 24 January 2022

Published: 26 January 2022

Publisher's Note: MDPI stays neutral with regard to jurisdictional claims in published maps and institutional affiliations.

Copyright: (c) 2022 by the authors. Licensee MDPI, Basel, Switzerland. This article is an open access article distributed under the terms and conditions of the Creative Commons Attribution (CC BY) license (https:/ / creativecommons.org/licenses/by/ $4.0 /)$.

\begin{abstract}
Cardiovascular diseases (CVDs) carry significant morbidity and mortality and are associated with substantial economic burden on healthcare systems around the world. Coronary artery disease, as one disease entity under the CVDs umbrella, had a prevalence of $7.2 \%$ among adults in the United States and incurred a financial burden of 360 billion US dollars in the years 2016-2017. The introduction of artificial intelligence (AI) and machine learning over the last two decades has unlocked new dimensions in the field of cardiovascular medicine. From automatic interpretations of heart rhythm disorders via smartwatches, to assisting in complex decision-making, AI has quickly expanded its realms in medicine and has demonstrated itself as a promising tool in helping clinicians guide treatment decisions. Understanding complex genetic interactions and developing clinical risk prediction models, advanced cardiac imaging, and improving mortality outcomes are just a few areas where AI has been applied in the domain of coronary artery disease. Through this review, we sought to summarize the advances in AI relating to coronary artery disease, current limitations, and future perspectives.
\end{abstract}

Keywords: artificial intelligence; coronary artery disease; major adverse cardiovascular events; fractional flow reserve; cardiac computed tomography

\section{Introduction}

Clinically significant atherosclerosis of the coronary arteries, known as coronary artery disease (CAD), is an endemic condition that is associated with significant morbidity and mortality [1]. For instance, CAD is reported to have affected 20.1 million American adults between 2015 and 2018 [2]. Current societal guidelines emphasize the importance of early detection and risk stratification in the appropriate age and risk groups, with the goal of implementation of goal-directed medical therapies that can alter the natural trajectory of CAD to a less morbid course [3]. Traditional population-derived primary and secondary prevention cardiovascular risk assessment tools (e.g., Framingham risk score, ASCVD, TIMI score, GRACE score, etc.) have historically relied on patient-level data that are easily retrievable and practical to utilize in the clinical setting. Despite their importance, such tools are inherently limited by design due to relying on regression models that make many mathematical assumptions that often do not hold in a real-world setting, such as collinearity between variables and homogeneity of effects. The complex nature and 
multifactorial pathology of CAD make such regression-based tools less generalizable across different populations.

Recently, the digitization of health records has improved access to large repositories of clinical and imaging datasets for clinical care and research purposes. This is coupled with advances in diagnostic tools that are available for the detection and quantification of CAD. To that end, recent studies have highlighted the usefulness of these tools in enhancing risk assessment and decision making through incorporation of different yet complementary findings from these imaging modalities (e.g., quantitative and qualitative plaque features on computed tomographic imaging of the coronary circulation, coupled with functional and physiologic findings on stress-test imaging). In addition, there has been an increasing interest in using the plethora of data in electronic health records and genomic data for better risk assessment [4]. Such tools are being integrated in practice as complementary methods to traditional tools [5-7].

Yet, despite the ever-increasing amounts of data, risk-prediction methods have been historically limited by what was possible with traditional statistical tools. The concept of Artificial Intelligence (AI) was introduced to mankind as early as the 1950s, with its employment in medical sciences commencing in the 1970s [8]. AI has gained momentum recently, fueled by an improvement in computational power, accumulation of data, and cloud processing. With the attempt to transfer a significant portion of human intelligence to machines, there has been a concerted effort aimed at harnessing the power of AI for biomedical applications in the past two decades $[9,10]$. Machine learning (ML) is a subfield of AI that involves the creation of algorithms that analyze large datasets without prior assumptions and learn rules and patterns between variables to make predictions and classifications [11]. On the other hand, deep learning (DL) is a subset of ML geared towards image analysis and utilizes more intricate algorithms known as neural networks with multiple deep, hidden layers. Specifically, while ML usually relies on structured data with handcrafted features often in tabular form, DL algorithms can input both structured and raw, unstructured data (e.g., images, video, and text) and extract their own features.

ML algorithms can incorporate a larger number of variables from different modalities, including both patient-level clinical parameters as well as two- and three-dimensional imaging data that take into account the multidimensional nonlinear interactions between variables [11]. Implementing such techniques in healthcare mainly aims to improve the accuracy of risk prediction and customize clinical decisions to each individual, which is the overarching theme in the goal of achieving precision medicine. In this paper, we summarize the recent advances in $\mathrm{ML}$ and current attempts at improving predictive analytics with relevance to $\mathrm{CAD}$. We also elucidate on the role of $\mathrm{AI}$ in genetics, the incremental role of $\mathrm{AI}$ in improving post-procedure risk prediction and long-term mortality. Lastly, we discuss the limitations and potential near-future applications of $\mathrm{AI}$ within cardiovascular medicine.

\section{Integration of Genetics and AI in Cardiovascular Diseases}

Over the last two decades, the emergence of technologies able to measure biological processes at a large scale have resulted in an enormous influx of data. For instance, the completion of the Human Genome Project has paved the way to design single-nucleotide polymorphism (SNP) and mRNA microarrays, which can broadly test for millions of genetic variants in a simple point-of-care test. This has paved the way for the emergence of modern data-driven sciences such as genomics and other "omics" [12]. Genome-wide association studies (GWASs) operate by simultaneous comparison of millions of SNPs between diseased individuals and disease-free controls to detect a statistically significant association between an SNP locus and a particular condition [12]. Erdmann et al. reported that up until the year 2018, GWASs have successfully identified 163 distinct genetic loci for SNPs that are associated with CAD [13]. The risk for expressing a complex trait like $\mathrm{CAD}$ can be represented by a mathematical model that assumes a normal distribution of a binary outcome (i.e., CAD or no CAD) and captures the aggregate influence of multiple genetic variants that are predisposed to disease. Such a model is referred to as a polygenic 
risk score (PRS). PRSs were proposed early on to improve risk stratification in CAD risk models, especially when combined with traditional cardiovascular risk factors. However, the complex genetic architecture along with the multifactorial nature of CAD have been major challenges in CAD risk prediction [14]. For instance, Kathiresan et al. built a genetic risk score to predict major adverse cardiovascular events based on nine different dyslipidemia-related SNPs previously identified in GWASs. Adding the genetic score to a Cox proportional hazard model along with traditional risk factors did not improve predictive accuracy as measured by the $C$ statistic model; however, there was a significant improvement in the net reclassification index, which accounts for correct movement of categories (assigning high-risk for patients who developed the disease, and low-risk for those who were disease-free) [15]. Brautbar et al. also suggested a genetic risk score to predict coronary heart disease based on SNPs. Adding the genetic risk score to traditional risk factors in a Cox proportional hazard model only modestly improved the area under the curve (AUC) for prediction of coronary heart disease from 0.742 to $0.749(\Delta=0.007$; 95\% CI, 0.004-0.013) [16]. ML and particularly DL algorithms are inherently designed to extract patterns and associations from large-scale data, including clinical and genomic data. Given the complexity and multifaceted nature of cardiovascular diseases in general, and CAD in particular, an approach that integrates all these factors into a risk-stratification model would be expected to better predict incident events than existent models [17].

Multiple studies have emphasized the role of ML in identifying genetic variants and expression patterns associated with CAD from mRNA arrays using differential expression analysis and protein-protein interaction networks [18,19]. For example, Zhang et al. used ML to perform differential expression analysis on mRNA profiles from CAD patients and healthy controls to identify a set of differentially expressed genes between the two groups, then built a network representation of functional protein-protein interaction. The top 20 genes in the network were identified using a maximal clique centrality (MCC) algorithm. Finally, to test the performance, a logistic regression model was built using the top five predictor genes to classify individuals into the presence or absence of CAD. The model achieved an AUC of 0.9295 and 0.8674 in the training and internal validation sets respectively [20].

Dogan et al. built an ensemble model of eight random-forest (RF) classifiers to predict the risk of symptomatic CAD using genetic and epigenetic variables along with clinical risk factors. The model was trained on a cohort derived from the Framingham heart study $(n=1545)$ and utilized variables derived from genome-wide array chips to extract epigenetic (DNA methylation loci) and genetic (SNP) profiles. The initial number of available variables were 876,014 SNP and DNA methylation (CpG) loci, which required multiple reduction steps, ending up with 4 CpG and 2 SNP predictors fed into the model along with age and gender. The model predicted symptomatic CAD with an accuracy, sensitivity, and specificity of $0.78,0.75$, and 0.80 , respectively, in the internal validation cohort $(n=142)$. For comparison, a similar ensemble model was built using clinical risk factors only as predictor variables and had an accuracy, sensitivity, and specificity of 0.65 , 0.42, and 0.89, respectively [21]. Pattarabanjird et al. tested multiple ML models to predict anatomical CAD severity (extent of diameter stenosis) in a binary fashion using clinical variables along with SNP loci. Quantitative coronary angiography and the Gensini score, which is a summation score that quantifies the severity of CAD by accounting for the segment-based most severe stenosis and the location of the stenosis within the coronary arteries, were used to assess model performance. The best-performing model (Sequential Neural Network; training set $n=325$ and internal validation set $n=82$ ) accurately classified CAD severity with AUC of 0.84 in the validation set [22]. Similarly, Naushad et al. trained ML models to predict the presence of CAD and the percentage of coronary diameter stenosis using clinical and genetic variables. The best-performing model (an ensemble model; training set $n=648$ ) accurately predicted CAD using 11 variables (clinical and genetic variants) with an AUC of 0.96 in the training set. The model also predicted the percentage of diameter stenosis with a correlation of $82.5 \%$ with the actual stenosis assessed 
using the gold-standard invasive angiography. However, these models were not internally nor externally validated [23].

Finally, the coronary artery calcium (CAC) score, calculated using the Agatston method on noncontrast ECG-gated cardiac computed tomography, is an established strong predictor of major adverse cardiovascular events in asymptomatic individuals. Genomic studies have previously focused on identifying genetic loci linked to CAC [24,25]. Oguz et al. suggested the use of ML algorithms to predict advanced CAC from SNP arrays and clinical variables. They identified a set of SNPs that ranked the highest in predictive importance and correlated with advanced CAC scores, defined as the 89th-99th percentile $\mathrm{CAC}$ scores in the derivation and replication cohorts, and trained different RF models to predict advanced CAC scores using clinical and genetic variables. Adding SNPs to clinical variables significantly improved AUC from $0.61 \pm 0.02$ to $0.83 \pm 0.01 ;(p<0.001)$ [26] for prediction of advanced CAC scores.

\section{Risk Prediction Models and Imaging Modalities for Estimating Pretest Probability of CAD}

Traditionally, stratifying patients presenting with stable chest pain using pretest probability (PTP) estimates of CAD has been commonly used to help with decision-making regarding downstream testing and the choice of an appropriate diagnostic modality. Historically, the Diamond-Forrester model—developed using age, sex, and chest pain characteristics-was used as a clinician's risk stratification tool in predicting the PTP of CAD [27]. However, numerous studies showed its limitation in overestimating PTP by approximately threefold, especially in women [28]. This led to the development of the updated Diamond-Forrester model (UDF) and the CAD consortium score [29-31]. These scores, incorporating demographic and clinical risk factors, have been proven to be better at predicting the risk of CAD. Therefore, improving the ability to predict CAD using more accurate risk-assessment modeling is imperative, given the potential to reduce downstream testing and associated costs. Using clinical and demographic features, ML models have been employed to estimate the PTP of CAD [32-34]. In a recent multicenter cross-sectional study, a deep neural network algorithm based on the facial profile of individuals was able to achieve a higher performance than traditional risk scores in predicting PTP of CAD (AUC for the ML model 0.730 vs. 0.623 for Diamond -Forrester and 0.652 for the CAD consortium, $p<0.001$ ) [35]. Though the study is limited by the lack of external validity and low specificity $(54 \%)$, such approaches can potentially lead to a paradigm change in CAD management by facilitating earlier detection and initiation of primary prevention using readily available parameters, such as an individual's facial profile.

When available, a CAC score has been shown to add to the PTP of CAD, with a CAC score of zero identifying low-risk patients who might not need additional testing $[7,36]$. ML models, combining clinical and imaging parameters, have been shown to have higher predictive power than traditional risk scores when predicting the PTP of obstructive CAD $[37,38]$. Al'Aref et al. included 25 clinical and demographic features to devise a ML model which, when combined with the Agatston CAC score, fared better than the ML model or CAD consortium score alone or in combination with the CAC score (AUC 0.881 for $\mathrm{ML}+\mathrm{CAC}$ as compared to $0.866,0.773$, and 0.734 for the CAD consortium + CAC, ML model, and CAD consortium respectively, $p<0.05$ ) [38]. As expected, CAC, age, and gender were the highest-ranked features in the model (Figure 1). 
A

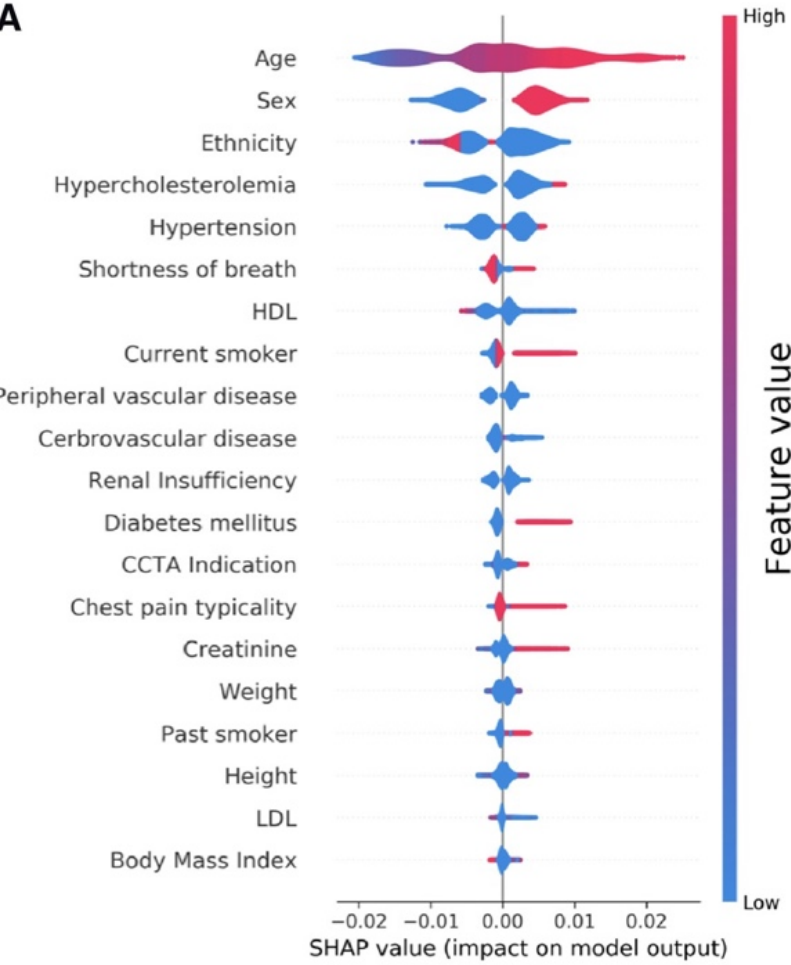

B

Coronary artery calcium score

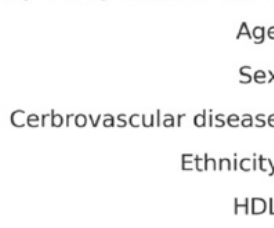

Hypercholesterolemia

Hypertension

Shortness of breath

Current smoker

Diabetes mellitus

Renal Insufficiency

Peripheral vascular disease

CCTA Indication

Weight

Chest pain typicality

Height

Creatinine

Past smoker

Body Mass Index

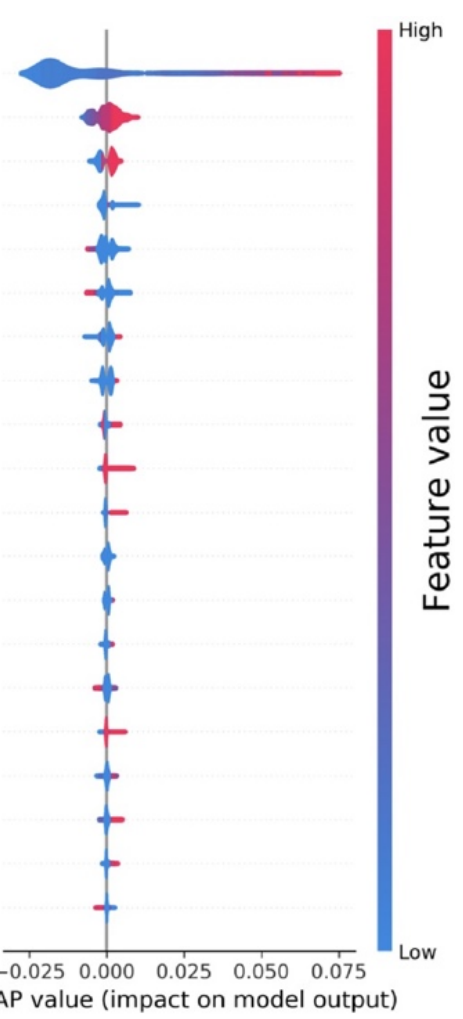

Figure 1. Feature ranking in the machine-learning model developed by $\mathrm{Al}^{\prime}$ Aref et al. based on clinical and demographic factors (A) and when combined with the Agatston calcium score (B), for the prediction of the presence of obstructive CAD on coronary CT angiography. A more positive SHAP (Shapley additive explanation value) indicates higher importance of the variable in the machinelearning model. Adapted with permission from Al'Aref et al. [38], Oxford University Press.

Various ML algorithms based on stress imaging, particularly single-photon emission computed tomography (SPECT), have been devised to facilitate the prediction of CAD. These models combined the clinical and demographic characteristics with the quantitative variables, as evaluated via SPECT to better predict CAD compared with the visual interpretation or quantitative variables alone [39-44]. More details about the parameters used to develop these models have been provided in Section 4, and a summary of the study results is included in Table 1.

Cardiac phase-space analysis is a novel noninvasive diagnostic platform that combines advanced disciplines of mathematics and physics with ML [45]. Thoracic orthogonal voltage gradient (OVG) signals from a patient are evaluated by cardiac phase-space analysis to quantify physiological and mathematical features associated with CAD. The analysis is performed at the point of care without the need for a change in physiologic status or radiation. Initial multicenter results suggest that resting cardiac phase-space analysis may have comparable diagnostic utility to functional tests currently used to assess CAD [46].

Finally, the assessment of regional wall motion abnormalities (RWMAs) on echocardiography has been associated with the presence of obstructive CAD, and as such can be useful in helping clinicians with downstream decision-making [47]. Recently, a deep-learning model developed by Kusunose et al. achieved performance similar to that of experienced cardiologists in the assessment of RWMAs on echocardiography (AUC of 0.99 vs. 0.98, $p=0.15$ ) [48]. Other than the assessment of obstructive CAD, machine learning has found its wide applicability in echocardiography to predict ventricular capacities, abnormal valvular function, as well as cardiac hemodynamics, the discussion of which is outside the scope of this review paper [49-51]. 
Table 1. Studies comparing ML models developed using SPECT variables with those using the qualitative or quantitative variables for prediction of CAD.

\begin{tabular}{|c|c|c|c|c|c|}
\hline Study & Center/Sample Size & ML Technology & Brief Description and Outcomes & Result & Limitations \\
\hline $\begin{array}{c}\text { Guner et al. [41] } \\
2010\end{array}$ & $\begin{array}{l}\text { Retrospective } \\
\text { Single-center study } \\
243 \text { patients }\end{array}$ & Artificial neural networks & $\begin{array}{l}\text { ML model trained from image data from } \\
\text { stress and difference (devised from rest } \\
\text { and stress maps) polar maps. } \\
\text { Outcome: ML model vs. expert } \\
\text { interpretation in the prediction of } \\
\text { obstructive (>70\% stenosis) CAD }\end{array}$ & $\begin{array}{l}\text { AUC } 0.74 \text { and } 0.84 \text { for ML and expert read, } \\
\text { no statistical difference found between } \\
\text { ML-trained model and expert read. }\end{array}$ & $\begin{array}{l}\text { Small sample size } \\
\text { Limited availability of } \\
\text { software used. }\end{array}$ \\
\hline $\begin{array}{l}\text { Arsanjani et al. [44] } \\
2013\end{array}$ & $\begin{array}{l}\text { Retrospective } \\
\text { Single-center study } \\
1181 \text { patients }\end{array}$ & Boosted ensemble & $\begin{array}{l}\text { ML model using quantitative variables } \\
\text { (TPD, stress/rest perfusion change, TID) } \\
\text { and clinical variables (age, sex, and } \\
\text { post-ECG probability) created. } \\
\text { Outcome: ML vs. visual analysis and TPD } \\
\text { in prediction of obstructive CAD. }\end{array}$ & $\begin{array}{l}\text { AUC: ML (quantitative }+ \text { clinical }-0.94 \text { ) } \\
>\text { ML (quantitative, } 0.90)>\text { combined } \\
\text { supine/prone TPD }-0.88 \text {. Also, better } \\
\text { than experts }(0.89 \text { and } 0.85 \text { for two } \\
\text { different experts). }\end{array}$ & $\begin{array}{l}\text { Dual isotope imaging protocol } \\
\text { used, leading to difficulty in } \\
\text { comparing rest and stress images. } \\
\text { No information was given on } \\
\text { localization of ischemia (didn't } \\
\text { provide information about the } \\
\text { culprit vessel). }\end{array}$ \\
\hline $\begin{array}{l}\text { Arsanjani et al. [39] } \\
2013\end{array}$ & $\begin{array}{c}\text { Retrospective } \\
\text { Single-center study } \\
957 \text { patients with no history } \\
\text { of CAD. }\end{array}$ & Support vector machines & $\begin{array}{l}\text { ML model using quantitative and } \\
\text { functional variables derived from SPECT. } \\
\text { Outcome: ML model vs. quantitative and } \\
\text { visual analysis in prediction of obstructive } \\
\text { CAD or LAD stenosis }>50 \% \text {. }\end{array}$ & $\begin{array}{l}\text { AUC: ML }(0.92)>\operatorname{TPD}(0.90)>\text { Expert } \\
\text { analysis (0.88 and } 0.87 \text { for two } \\
\text { different experts) }\end{array}$ & $\begin{array}{l}\text { 1. Limited generalizability (patients } \\
\text { with a history of CAD and valvular } \\
\text { disease were excluded). } \\
\text { Stenosis on CAG determined } \\
\text { qualitatively rather } \\
\text { than quantitatively. }\end{array}$ \\
\hline $\begin{array}{c}\text { Betancur et al. [43] } \\
2018\end{array}$ & $\begin{array}{l}\text { Retrospective } \\
\text { Multicenter study } \\
1638 \text { patients }\end{array}$ & Convolutional neural networks & $\begin{array}{l}\text { DL model developed from single-view } \\
\text { polar maps; trained and compared with } \\
\text { TPD for prediction of CAD. } \\
\text { Outcome: ML model vs. TPD for } \\
\text { prediction of obstructive CAD. }\end{array}$ & $\begin{array}{l}\text { DL > TPD on per patient (AUC } 0.80 \text { vs. } \\
0.78 \text { ) and per vessel level (AUC } 0.76 \text { vs. } \\
0.73 \text { ) for prediction of obstructive CAD, } \\
\qquad p<0.01 .\end{array}$ & $\begin{array}{l}\text { 1. Stenosis on CAG determined } \\
\text { qualitatively rather than } \\
\text { quantitatively. } \\
\text { 2. Only stress static images used to } \\
\text { train the algorithm. }\end{array}$ \\
\hline $\begin{array}{c}\text { Betancur et al. [40] } \\
2018\end{array}$ & $\begin{array}{c}\text { Retrospective } \\
\text { Multicenter study } \\
1160 \text { patients with no history } \\
\text { of CAD }\end{array}$ & Convolutional neural networks & $\begin{array}{l}\text { DL model developed to automatically } \\
\text { combine upright and supine MPI } \\
\text { polar maps. } \\
\text { Outcome: ML model vs. TPD for } \\
\text { prediction of obstructive CAD. }\end{array}$ & $\begin{array}{l}\mathrm{DL}>\mathrm{TPD} \text { on per patient (AUC } 0.81 \mathrm{vs} \text {. } \\
0.78 \text { ) and per vessel (AUC } 0.77 \mathrm{vs} .0 .73 \text { ) for } \\
\text { prediction of obstructive CAD, } p<0.001\end{array}$ & $\begin{array}{ll}\text { 1. } & \text { Stenosis on CAG } \\
\text { determined visually. } \\
\text { 2. }\end{array}$ \\
\hline $\begin{array}{l}\text { Rahmani et al. [42] } \\
2019\end{array}$ & $\begin{array}{l}\text { Retrospective } \\
\text { Single-center study } \\
93 \text { patients }\end{array}$ & Artificial neural networks & $\begin{array}{l}\text { ML model created using clinical, } \\
\text { demographic, and polar-map data. } \\
\text { Outcome: ML model vs. expert } \\
\text { interpretation in prediction of obstructive } \\
\text { CAD and abnormal angiographic results. }\end{array}$ & $\begin{array}{c}\text { Accuracy for ML vs. visual interpretation } \\
\text { for prediction of: } \\
\text { Obstructive CAD: } 85.7 \% \text { vs. } 65.0 \% \\
\text { Abnormal angiographic results: } \\
92.9 \% \text { vs. } 81.7 \%\end{array}$ & $\begin{array}{l}\text { Small sample size } \\
\text { Patients with a high pretest } \\
\text { probability included, hence } \\
\text { possible over- and underestimation } \\
\text { of sensitivity and } \\
\text { specificity respectively. }\end{array}$ \\
\hline
\end{tabular}

CAG: coronary angiography; LAD: left anterior descending; MPI: myocardial perfusion imaging, TPD: total perfusion deficit, TID: transient ischemic dilation. 


\section{Artificial Intelligence in Management of CAD in the Emergency Department}

Chest pain is a common emergency department presentation, and distinguishing cardiac from noncardiac pain causes is crucial for optimal management. Modalities such as electrocardiography (ECG) serve as a quick way to recognize patterns associated with unstable CAD, and in particular acute coronary syndromes (ACSs). Deep neural networks have shown a consistent performance in image recognition, and models have hence been devised to identify patterns related to CAD and myocardial infarction (MI) [52-54]. By reducing interobserver variability and providing accurate results efficiently, this approach holds the promise of improving workflow across healthcare systems, while helping patients in areas of limited medical infrastructure and specialized care.

Cardiac biomarkers, such as high-sensitivity troponin, have been well-validated as markers of myocardial ischemia and damage [55]. High-sensitivity troponin I (hs-cTnI) assay forms the core of the 'rule in and rule out' clinical decision pathway as per ESC 2020 chest pain guidelines and 2021 ACC / AHA chest pain guidelines [36,56]. For instance, a very low hs-cTnI at hospital admission or a negative one-hour delta troponin (in the background of a low hs-cTnI value at admission) has a high negative predictive value (>99\%) for ACS [57-61]. On the other hand, a high admission hs-cTnI value or a significant increase in values in an hour portends a high positive-predictive value (70-75\%), warranting additional downstream testing $[56,62,63]$.

Using the strategy mentioned above, approximately one-third of the patients fall in the 'indeterminate' zone. Diagnosis and management of this group is challenging, necessitating an approach based on clinical history, pre-existing risk factors, serial hs-cTnI trends, and further imaging. A recent ML model based on three clinical (age, sex, and prior percutaneous coronary intervention) as well as levels of three biomarkers (hs-cTnI, KIM-1, and adiponectin) demonstrated excellence in predicting obstructive CAD in the validation cohort (AUC 0.86 for prediction of $>50 \%$ diameter stenosis) [64]. Notably, the model performed remarkably well in patients in the 'indeterminate' zone, with AUC of 0.88 and a positive predictive value of $93 \%$, hence identifying patients who will benefit from further testing.

The 2021 American College of Cardiology/American Heart Association (ACC/AHA) chest pain guidelines advocate for the use of coronary CT angiography (CCTA) in intermediate-risk patients presenting with acute chest pain who either have no known history or a history of nonobstructive CAD (defined as coronary artery disease with less than 50\% diameter stenosis) [36]. Given the ability of CCTA to accurately define coronary anatomy and extent/distribution of atherosclerotic plaque, it has been consistently shown to be a useful noninvasive imaging modality for patient selection, particularly for those who might require further invasive evaluation. However, interpretation of CCTA scans requires expertise and is time-intensive. Therefore, automatic interpretation of CCTA, which can lead to a significant reduction in the processing times, is highly desirable. ML algorithms have recently been developed, achieving a 70-75\% reduction in reading time compared to that required for human interpretation (2.3 min for AI vs. 7.6-9.6 min for human readers). Though the model described performed slightly lower than highly experienced readers in interpreting CCTA (AUC 0.93 vs. 0.90 for human vs. AI, $p<0.05$ ), when combined with low-experience human readers, it augmented the reader's ability to correctly reclassify obstructive CAD (per-vessel net reclassification index (NRI) $0.07, p<0.001$ ) [65]. In addition, ML has been applied for various segmentation and classification tasks on cardiac CT imaging, from automatic segmentation of calcified and noncalcified plaque to automated calculation of the Agatston CAC score, and finally quantification of cardiac structures on CT imaging (Figure 2) [66-73]. Therefore, the application of ML could provide reliable results in real time, while bridging the dearth of experts in low-resource settings. 


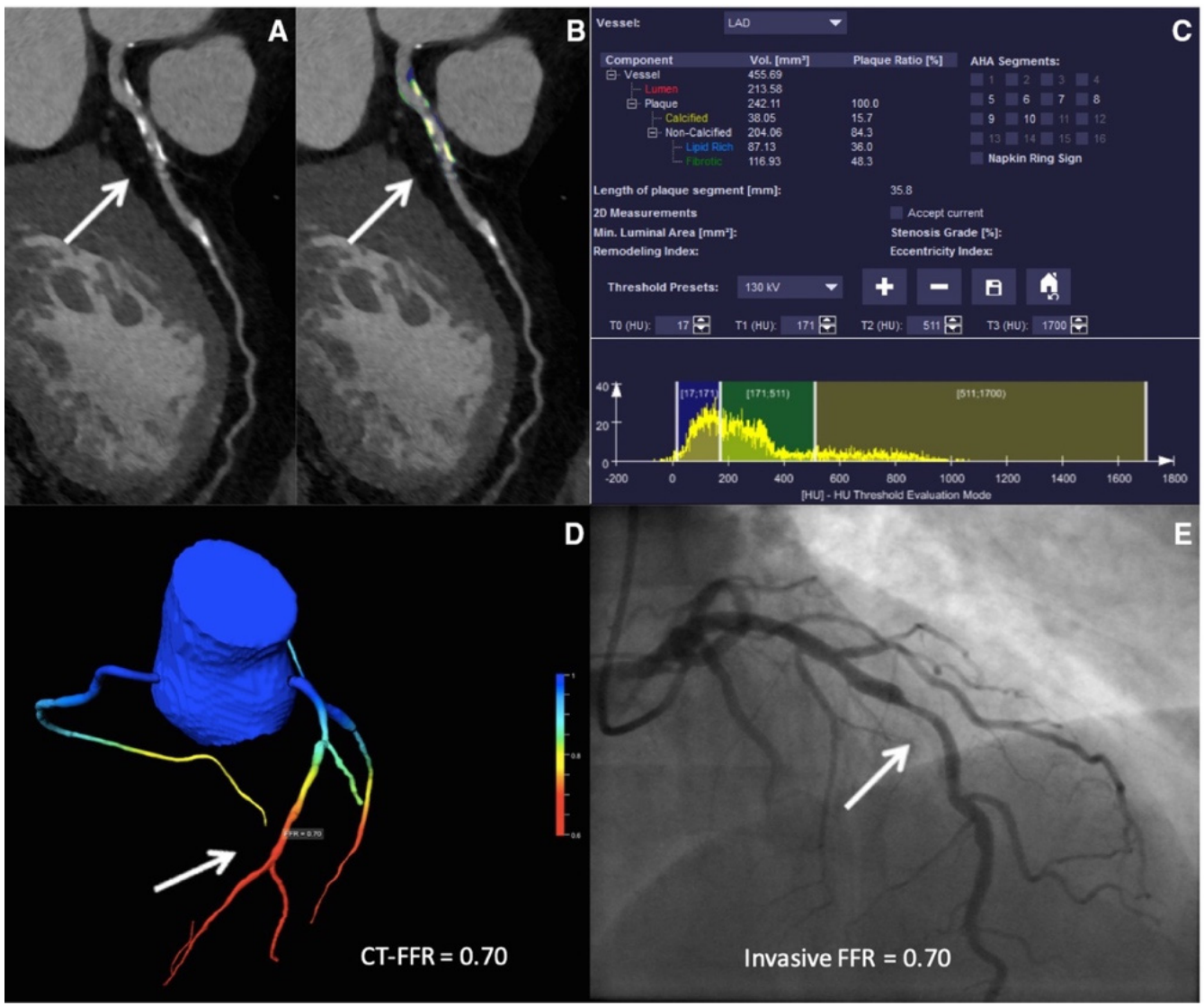

Figure 2. ML-based fractional flow reserve from cardiac CT (CT-FFR $\left.\mathrm{ML}_{\mathrm{L}}\right)$. Machine-learning-based coronary plaque analysis quantifies atherosclerotic plaque into calcified and noncalcified components $(\mathbf{A}, \mathbf{B})$. This is further integrated with other quantitative parameters $(\mathbf{C})$ and transformed into 3-D images of the vessels to give CT-FFR $\mathrm{ML}_{\mathrm{ML}}(\mathrm{D})$, which has been shown to have a good correlation with invasive fractional flow reserve (FFR-E). Adapted with permission from Von Knebel Doeberitz et al. [65], Elsevier.

Stress testing, which provides an estimate of myocardial perfusion and viability, has been recommended as an alternative to CCTA in intermediate-risk chest pain patients [36]. Myocardial perfusion imaging, particularly SPECT, has been employed to recognize patients who might need an invasive evaluation, with a diagnostic sensitivity of $75-88 \%$ and specificity of $60-79 \%$ [74-79]. SPECT can be evaluated qualitatively in terms of size, severity, location, and reversibility of perfusion defect, and quantitatively, in terms of total perfusion deficit (TPD), summed stress score (SSS), summed rest score (SRS), as well as stress and rest volumes [80]. Automatically generated polar maps (representing radiotracer distribution in a two-dimensional plane) after three-dimensional segmentation of the left ventricle (LV) have been used as raw data for quantitative analysis. After the LV polar map is divided into 17 segments, each of the segments is graded on a scale of $0-4$ based on the severity of ischemia. The scores are then summated to generate SSS and SRS [81]. Polar maps also provide information about the overall extent and magnitude of ischemia, in terms of TPD [81,82]. These objective variables extracted from the quantitative analysis offer an increased degree of reproducibility and can be incorporated into risk scores to predict mortality $[82,83]$. The diagnostic accuracy of qualitative and quantitative approaches is comparable, as has been shown in numerous studies [84]. A deep convolutional neural network-based model derived from polar maps (Figure 3) had a superior performance compared to TPD in predicting obstructive coronary artery disease (the AUC for ML were 0.80 and 0.76 vs. 0.78 and 0.73 for TPD on a per-patient and per-vessel basis respectively, $p<0.01$ ). In addition to diagnosis, models to predict early revascularization ( $<90$ days from 
SPECT) have been developed and have demonstrated better performance than individual SPECT variables on a per-patient and a per-vessel level $[85,86]$.

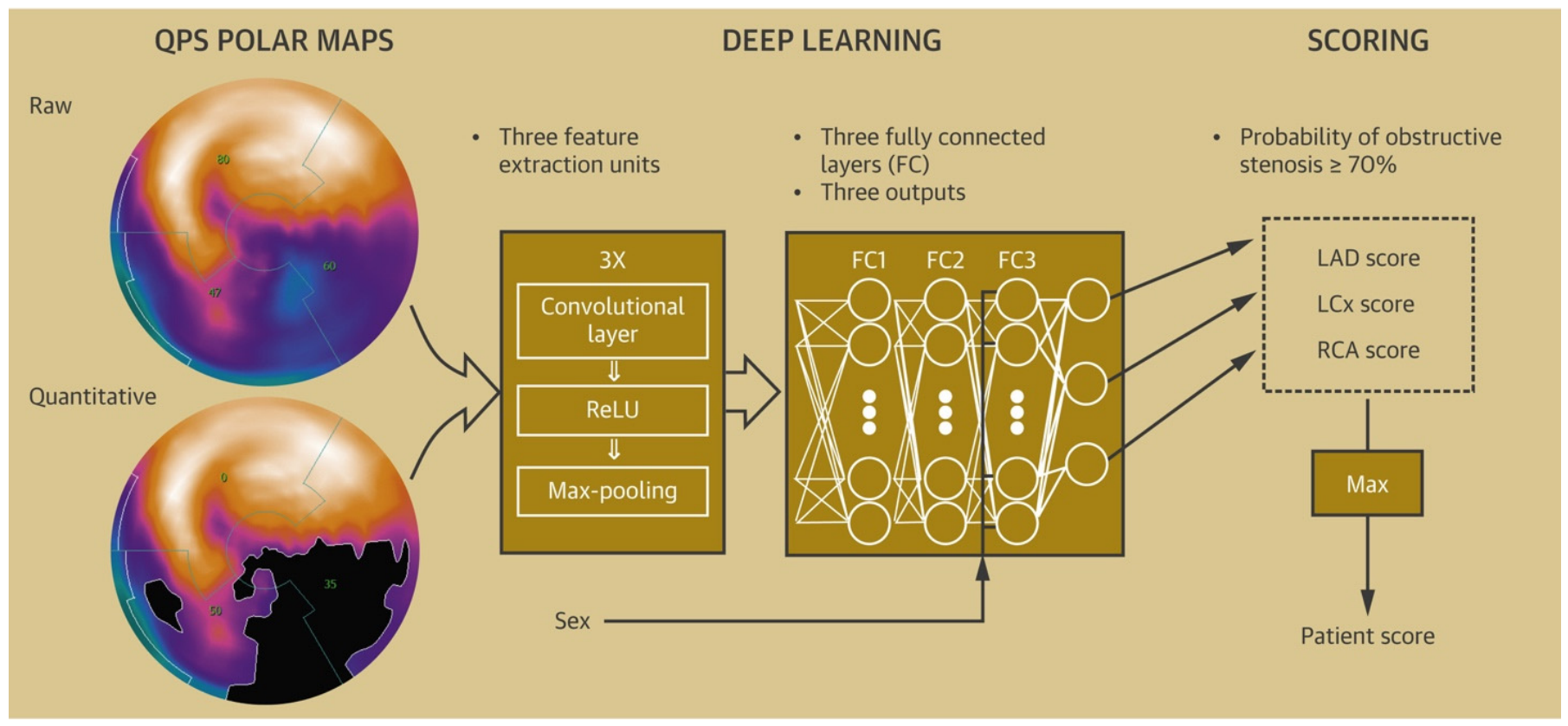

Figure 3. Deep-learning model to predict obstructive CAD from polar maps. Raw polar maps and extent polar maps (maps with abnormal pixels representing ischemia blackened out) are fed into deep neural networks, with the extracted data used to calculate scores for individual vessels to predict the probability of CAD. Adapted with permission from Betancur et al. [43], Elsevier.

\section{Artificial Intelligence to Predict Functionally Obstructive CAD and Lesion-Specific Ischemia-As a Gatekeeper to the Catheterization Laboratory}

One of the inherent limitations of CCTA is its limited ability to predict the functional significance of coronary stenosis. To overcome this shortcoming, CT-derived fractional flow reserve $\left(\mathrm{FFR}_{\mathrm{CT}}\right)$ was developed based on the critical concept of computational fluid dynamics (CFD), with numerous trials demonstrating its strong correlation with invasive fractional flow reserve (FFR) as determined by invasive coronary angiography (ICA) [87-90]. Rabbat et al. demonstrated that $\mathrm{FFR}_{\mathrm{CT}}$ added to CCTA safely deferred ICA in patients with CAD of indeterminate hemodynamic significance. In addition, a high proportion of those who underwent ICA were revascularized [91]. These studies and others led to FFR $\mathrm{CT}_{\mathrm{T}}$ being incorporated in the $2021 \mathrm{ACC} / \mathrm{AHA}$ chest pain guidelines in intermediate-risk patients to detect lesion-specific ischemia in proximal or middle segments of the coronary arteries and determined to have atherosclerotic plaque with $40 \%$ to $90 \%$ diameter stenosis [36]. Despite its excellent correlation, the off-site computation of $\mathrm{FFR}_{\mathrm{CT}}$ hampers its use in real time, owing to the need for longer processing times [92]. To overcome this limitation and to allow for quick computation of a value for the functional significance of a particular lesion, novel ML approaches based on artery lumen segmentation [93], left ventricular myocardial segmentation [94,95], and artery centerline tracking [96], have been proposed.

\subsection{ML-Based CT-FFR Estimation and Diagnostic Accuracy}

Based on the concept of artery lumen segmentation, the ML-based FFR estimation $\left(\mathrm{CT}-\mathrm{FFR}_{\mathrm{ML}}\right.$ ) has generated significant interest in the past few years. The CT-FFR $\mathrm{ML}_{\text {model }}$ was trained on 12,000 synthetically generated coronary geometric datasets and used deep neural networks, allowing for automatic computation of FFR in real-time [93]. Coenen et al. performed a multicenter, prospective study to evaluate the diagnostic performance of CT-FFR ${ }_{M L}$ to predict lesion-specific ischemia, comparing it with traditional CCTA parameters, with invasive FFR being the gold standard [97]. They demonstrated an excellent corre- 
lation between CT-FFR $\mathrm{ML}_{\mathrm{L}}$ and $\mathrm{FFR}_{\mathrm{CT}}(\mathrm{r}=0.997)$ and a superior performance of CT-FFR $\mathrm{ML}$ over traditional CCTA in predicting lesion-specific ischemia (AUC: 0.84 vs. $0.69, p<0.001$ on a per-vessel level). Since then, multiple retrospective studies have been performed to evaluate the diagnostic accuracy of CT-FFR $\mathrm{ML}$, validated against the gold-standard invasive FFR. They have further demonstrated superior diagnostic performance of CT-FFR $\mathrm{ML}_{\mathrm{L}}$ over CTA stenosis severity and quantitative atherosclerotic plaque features derived from CCTA [70,93,97-107].

To further highlight the incremental diagnostic value of CT-FFR $\mathrm{ML}_{\text {over anatomic }}$ plaque features derived from CCTA in vessels with intermediate stenosis, several other studies have been performed $[99,102,103,106]$. Tang et al. evaluated the diagnostic value of CT-FFR $\mathrm{ML}_{\mathrm{L}}$ in predicting lesion-specific ischemia [103]. Based on a study sample of

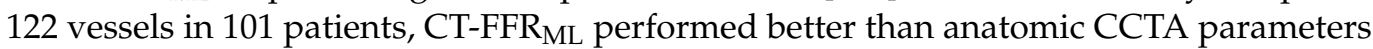

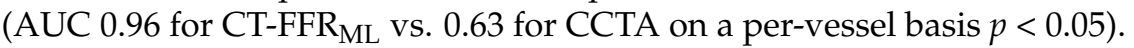

\subsection{Impact of Calcification Burden on the Performance of CT-FFR $R_{M L}$}

The impact of coronary calcification on the diagnostic performance of CCTA has been well-established, with more extensive calcification limiting the ability of CCTA to evaluate for the presence of obstructive CAD [108-110]. Multiple indices have been devised to compute a CAC score, with the Agatston score, calcium volume, calcification remodeling index (CRI), and segmental arc calcification method being common examples [111]. The Agatston Score (AS) is the most widely validated approach, which summates the calcium score (function of peak density and area of the lesion) of the individual lesions across all coronary artery segments [112]. CRI provides a lesion-specific calcium estimate and is calculated as a ratio of the cross-sectional luminal area of the most severely calcified site to the proximal luminal area [113]. The segmental arc calcification method estimates lesion-specific calcium burden by measuring the greatest circumferential extent of coronary calcium, grading as nil (noncalcified), mild $\left(0-90^{\circ}\right)$, moderate $\left(90-180^{\circ}\right)$, and severe $\left(>180^{\circ}\right)$ calcification [110,114]. Recent studies have evaluated the performance of CT-FFR $\mathrm{ML}_{\text {with }}$ varying calcification burden as assessed by the parameters mentioned above $[97-99,104]$. Tesche et al. did a retrospective analysis using 482 vessels in 314 patients to evaluate the impact of calcifications on the performance of CT-FFR ${ }_{M L}$ [104]. They showed a statistically significant decrease in discriminatory power of CT-FFR $\mathrm{ML}_{\mathrm{L}}$, measured in terms of AUC with increasing Agatston scores (AUC for CT-FFR $\mathrm{ML}_{0.85}$ and 0.81 in low-intermediate Agatston score (1-400) and high Agatston score ( $>400)$ ranges respectively, $p=0.04)$.

Di Jiang et al. [98] evaluated the impact of calcification arc and CRI on the performance of CT-FFR $\mathrm{ML}$. No statistically significant difference was found in the discriminatory power of CT-FFR $\mathrm{ML}_{\mathrm{M}}$ with increasing calcification burden. In the proportion of patients where the Agatston score was available, there was no difference in the diagnostic performance of CT-FFR ${ }_{M L}$ across severity of calcification. The difference from Tesche et al. can be explained by a lower mean Agatston score ( 288 vs. 492 and 138 vs. 187 at a per-patient and per-vessel level, respectively) and smaller sample size $(n=150)$ for whom the Agatston score was available, resulting in low power to detect a difference.

Furthermore, Koo et al. [99] carried out a similar study and found no impact of increasing Agatston score on the performance of CT-FFR $\mathrm{ML}$. Interestingly, a sizeable proportion of the sample had higher coronary calcification (mean Agatston score of 311 on a per-vessel basis). More research in this area is needed in order to further validate the diagnostic performance of CT-FFR $\mathrm{ML}_{\mathrm{ML}}$ across varying degrees of coronary calcification.

\subsection{CT-FFR $R_{M L}$ in Predicting Revascularization Events}

CT-FFR $\mathrm{ML}_{\mathrm{L}}$ has been shown to be a better predictor than plaque features derived from CCTA for the determination of the presence of lesion-specific ischemia, but whether CT-FFR $\mathrm{ML}_{\mathrm{L}}$ influences the eventual treatment plan and outcomes (as guided by ICA-FFR) remains an active area of investigation [115-118]. Qiao et al. demonstrated the added benefit of CT-FFR $\mathrm{ML}_{\mathrm{ML}}$ compared to relying on an anatomy-based strategy in patients with 
stable chest pain (reduction rate of ICA by $54.5 \%$ and $4.4 \%$ fewer revascularizations) [115]. Additionally, this study demonstrated that adding CT-FFR $\mathrm{ML}_{\mathrm{ML}}$ to CCTA can decrease the rate of unnecessary ICA by $35.2 \%$ (thereby increasing the proportion of revascularizations when ICA is undertaken), truly acting as a gatekeeper to ICA. Furthermore, lower CT-FFR ${ }_{M L}$ was associated with higher major adverse cardiovascular event (MACE) risk when compared to diameter stenosis on CCTA (HR, 6.84 vs. 1.47) or ICA (HR, 6.84 vs. 1.84). Liu et al. found a similar rate of MACE $(2.9 \%)$ after revascularization based on either combining CCTA stenosis $\geq 50 \%$ and CT-FFR $\mathrm{ML} \leq 0.8$ or ICA stenosis $\geq 75 \%$ in a 2-year follow-up [116]. This study further highlighted the use of CT-FFR $\mathrm{ML}_{\text {a }}$ a gatekeeper to ICA with a positive impact on lower healthcare costs.

CT-FFR $\mathrm{ML}_{\mathrm{ML}}$ comes with its own set of shortcomings. The diagnostic performance of the CT-FFR $\mathrm{ML}_{\mathrm{ML}}$ model is lower, with the invasive FFR closely approaching the diagnostic threshold of $0.8[97,99,119]$. Traditional statistical and DL approaches have shown that stenosis severity; plaque characteristics, such as low-density, noncalcified plaque; and remodeling index are independent predictors of lesion-specific ischemia that are not related to CT-FFR $\mathrm{ML}_{\mathrm{ML}}[120,121]$. An integrated DL approach in the future that combines clinical features, anatomical plaque characteristics, vessel features, and functional assessment could potentially overcome this limitation.

\section{Artificial Intelligence in the Field of Intracoronary Imaging}

During ICA, intravascular ultrasound (IVUS) and optical coherence tomography (OCT) have been widely adopted for coronary luminal imaging, and some of the main applications involve assessment of plaque burden and optimization of stent placement [122]. IVUS uses ultrasound waves to generate cross-sectional images of coronary vessels with axial and lateral resolution ranging from 70-200 microns and 200-400 microns, respectively [122-124]. The penetration depth of IVUS is $10 \mathrm{~mm}$, which allows for a complete cross-sectional analysis of the coronary vessel walls [124]. IVUS can help describe plaque characteristics, with high-risk plaques (plaques with large necrotic cores) appearing as areas of echoattenuation [125]. On the other hand, calcifications in the IVUS frame indicate a calcified plaque, with heavily calcified plaque increasing the risk of stent underexpansion during percutaneous coronary intervention (PCI) [126,127]. Virtual histology IVUS (VH-IVUS) is another technique derived from radiofrequency data from IVUS, allowing for in vivo assessment of plaque composition [128]. By characterizing plaque features and vessel dimensions, IVUS has found its pre-procedural role in the quantitative and qualitative assessment of atherosclerotic plaque as well as interventional planning, ranging from vessel dimension assessment and evaluation of stent placement. Post-procedurally, IVUS can be employed to visualize stent expansion, identify stent edge dissection, stent mal-apposition, and confirm the presence of in-stent thrombosis in the right clinical context $[129,130]$. Given the benefits, IVUS has been shown to optimize stent implantation and improve outcomes, including revascularization, MACE, and mortality when used routinely in the cardiac catheterization laboratory [130-132].

On the other hand, OCT works on the principle of near-infrared light waves, generating cross-sectional images with a much higher axial and lateral resolution of 10 microns and 20-40 microns, respectively [133]. This allows for a detailed view of the lumen-plaque interface, providing accurate dimensions of the luminal area and better plaque characterization. The vulnerability of a plaque is a function of the thickness of its fibrous cap, the size of the necrotic core, and the presence of macrophages. A thin, fibrous cap; sizeable necrotic core; and increased macrophages increase the risk of plaque rupture and subsequent ACS [113]. Given the high resolution provided by OCT, it is considered a gold-standard invasive imaging modality for detecting thin-cap fibroatheroma (TCFA), which, pathologically, is a precursor of vulnerable plaque and clinically proven to be an independent predictor of MACE [134]. A significant drawback of OCT is its inherent low penetration depth (1-2 mm), which makes IVUS a better modality for a full-thickness analysis of vessel wall [130]. 
Though fascinating, IVUS and OCT have a low adoption rate in the US, being employed only at tertiary-care centers owing to cost, need for additional procedural time, and the associated technical complexities $[135,136]$. By using deep-learning algorithms to optimize the workflow associated with image acquisition and interpretation, ML has the potential to reduce procedural costs and time required, which are the two major hindrances to the widespread use of IVUS and OCT.

\subsection{Artificial Intelligence to Optimize Peri-Intervention Workflow}

To predict OCT-derived TCFA on IVUS images, Bae et al. created a ML model, enrolling 517 patients who underwent ICA [137]. A total of 40,908 IVUS-OCT co-registered sections in 517 coronary arteries were divided into training and testing sets in a ratio of 4:1. An artificial-neural-network-based model using 17 features achieved the highest performance with a sensitivity and specificity of $85 \pm 4 \%$ and $79 \pm 6 \%$, respectively, and good discriminatory power (AUC of $0.80 \pm 0.08$ ). Larger plaque burden, minimal diameter, decreased lumen area, and increased lumen eccentricity were seen to be strongly associated with OCT-derived TCFAs. Min et al. utilized a deep learning algorithm (densely connected convolutional neural network) on 35,678 OCT frames to automatically detect TCFAs from OCT images [138]. After the frames were interpreted for the presence/absence of TCFA, data was fed into the algorithm to devise a deep-learning model. By achieving high sensitivity and specificity of $88.7 \pm 3.4 \%$ and $91.8 \pm 2.0 \%$ on the test data, such deeplearning models can significantly reduce processing times and allow for easy interpretation when it comes to identifying a vulnerable high-risk plaque.

As mentioned earlier, IVUS can help characterize high-risk plaques, which appear as areas of attenuation on IVUS frames due to the presence of a large necrotic core. Identifying such lesions becomes imperative to reduce the incidence of complications such as periprocedural MI. To accurately classify plaque characteristics and to facilitate detection of high-risk lesions, Cho et al. described a deep-learning algorithm to accurately differentiate IVUS segments as attenuated or calcified, or plaque without attenuation or calcification [139]. A total 598 vessels in 598 patients were evaluated, and a DL model with five-fold crossvalidation was developed. The deep-learning model closely correlated with the expert read, and correlation coefficients for calcification, attenuation, and no attenuation or calcification were $0.79,0.74$, and 0.99 , respectively (Figure 4 ).

Stent underexpansion is a frequently encountered entity that has been associated with an increased risk of in-stent restenosis. Studies have demonstrated the postprocedural minimum stent area (MSA) and IVUS-measured stent length to be independent predictors for in-stent restenosis [130,140-143]. Min et al. devised a deep-learning model to predict stent underexpansion based on pre-PCI IVUS frames [144]. They evaluated 618 coronary lesions from 618 patients undergoing pre- and postprocedural IVUS and divided them into training and testing sets in a 5:1 ratio. A convolutional neural network (CNN) model was used to predict the poststenting stent area. Features extracted from the $\mathrm{CNN}$ were combined with additional image-derived features via a boosted ensemble algorithm, which yielded sensitivity and specificity of $68 \%$ and $98 \%$, respectively, and an AUC of 0.95 to predict stent underexpansion. The stent areas and volumes predicted via the $\mathrm{CNN}$ correlated well with poststenting IVUS ( $\mathrm{r}$ for stent area and volume 0.832 and 0.958 , respectively). The most important features predicting stent underexpansion were luminal area, external elastic membrane (EEM) area (both at the reference and the target), and plaque area of the region of interest.

\subsection{Applications of Artificial Intelligence in Intra and Post-Intervention Workflow}

Optimal stent expansion is vital to successful outcomes, with stent underexpansion predisposing to stent restenosis and a greater stent expansion exposing the procedure to a risk of stent edge dissection [130]. IVUS, by allowing direct visualization of vessel architecture, can help in the earlier identification and management of these complications. Nishi et al. developed a ML model to compute the luminal area and the vessel area 
accurately, as well as the stent area, which exhibited an excellent correlation between ML-derived and expert-derived dimensions while dramatically reducing the time required for segmentation of IVUS images (37 s) compared with expert analysis (30 h) [145].

Virtual histology IVUS (VH-IVUS) is a well-studied intracoronary imaging modality used for in vivo visualization of high-risk plaques [146-149]. Zhang et al. devised a deeplearning model to predict the location of high-risk plaques in nonculprit vessels in patients who underwent IVUS at baseline and after one year [150]. Though large-scale validation is required, the model predicted the occurrence of TCFAs, plaque burden $>70 \%$, and minimal luminal area $\leq 4 \mathrm{~mm}^{2}$ reasonably well at a one-year follow-up on a per-lesion level.

A
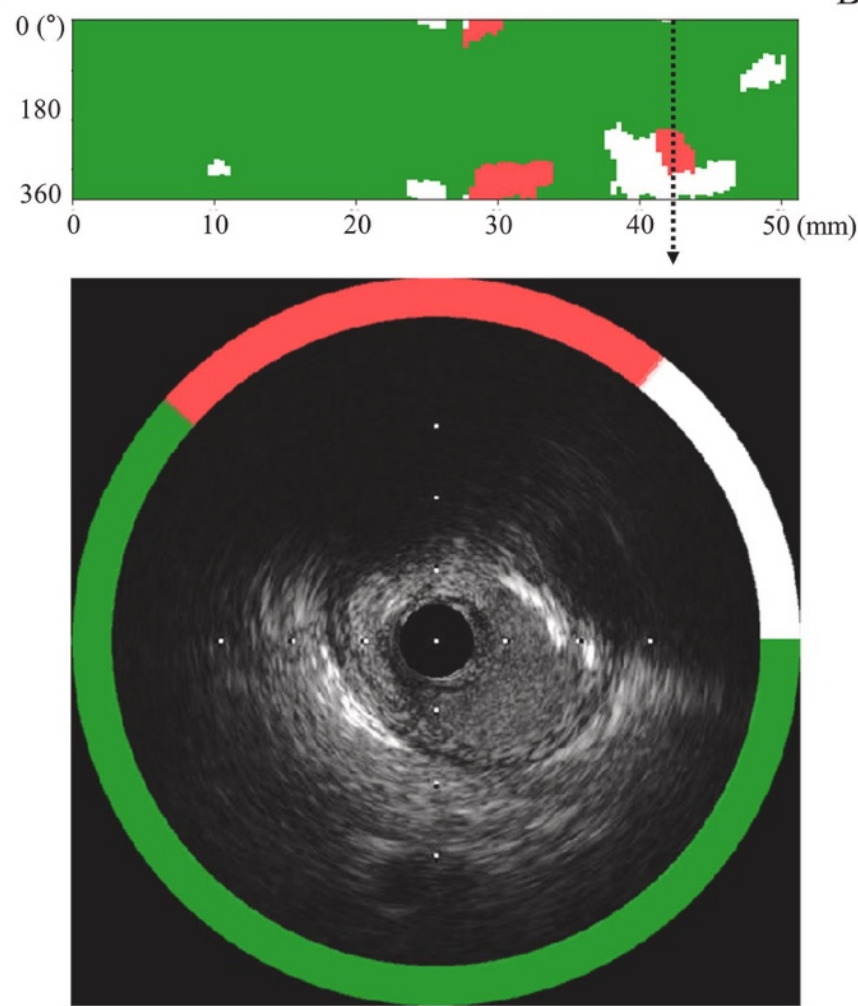

$\mathrm{B}$
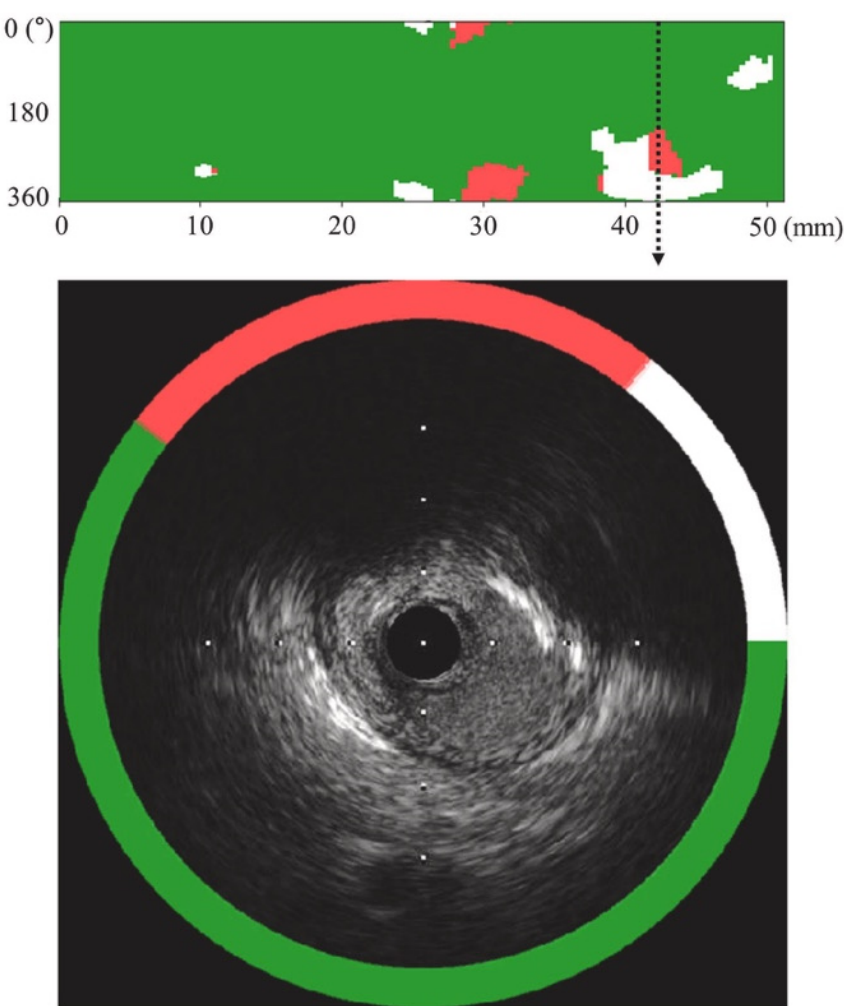

Figure 4. ML(A) vs. human (B) interpretations for plaque characterization for IVUS images. The upper panel shows representation of plaque features along the long axis of the vessel $(x$-axis represents the distance from ROI (region of interest) and $y$-axis represents the angular position $\left(0-360^{\circ}\right)$ of the plaque. The lower panel shows the plaque characterization on a cross-sectional view of the IVUS frame. Attenuation, calcification, and regions without attenuation or calcification are represented by red, white, and green respectively. Adapted with permission from Cho et al. [135], Elsevier.

\section{Artificial Intelligence-Based Post-Procedure Risk Prediction Models}

In addition to early detection and the institution of guideline-directed therapy in the appropriate risk strata, accurate prediction of unheralded adverse events forms the cornerstone for managing CAD. Identifying the high-risk target population can potentially provide a window for aggressive risk factor modulation, thereby reducing mortality and contributing towards better health at a population level. Multiple risk-prediction models have been developed to predict in-hospital mortality and the long-term risk of MACE in high-risk cohorts [151-158].

PCI is a relatively safe procedure, with a reported overall in-hospital mortality rate of $1-2 \%$ [159]. The risk of complications increases with increasing patient morbidity, with an incidence of technical difficulties and periprocedural complications 2.2 times higher than in the average population [160]. The Mayo clinic risk score (MCRS) and New York State risk score (NYSRS) were developed to predict in-hospital and 30-day mortality in 
patients undergoing PCI. Both scores performed equivalently well, showing an excellent discriminative ability to identify patients at a higher risk for in-hospital and 30-day mortality [161]. They employed regression-based models, assuming a linear interplay between patient variables and mortality outcomes. ML models have been recently developed to potentially uncover complex and nonlinear relationships between multiple factors, hence improving diagnostic accuracy over current models.

Zack et al. evaluated 11,709 patients to train two RF regression models-one using 52 demographic and clinical parameters to predict in-hospital mortality and the second model also incorporating 358 discharge variables in addition to the 52 admission parameters to predict 180-day cardiovascular mortality and 30-day heart failure rehospitalization [162]. They compared the model performances against logistic regression models trained using the same variables. No significant difference was found between the RF model and logistic regression in predicting in-hospital mortality (AUC 0.923 vs. $0.925, p=0.84$ ). The ML model performed significantly better than the logistic regression model for prediction of 30-day heart failure hospitalizations (AUC 0.899 vs. $0.846, p=0.003$ ) and 180-day cardiovascular death (AUC 0.881 vs. $0.812, p=0.02$ ).

$\mathrm{Al}^{\prime}$ Aref et al. [163] developed a supervised machine learning approach to predict in-hospital mortality among patients undergoing PCI. Utilizing 479,804 patients from the New York state registry, they utilized 49 clinical, angiographic, and periprocedural event characteristics to create a ML model via adaptive boosting. It performed better than the logistic regression model (AUC 0.927 for ML vs. 0.908 for logistic regression, $p<0.01$ ). Age and ejection fraction emerged as the most important variables predicting mortality.

Periprocedural bleeding is one of the most common complications of PCI and has been linked to adverse in-hospital outcomes [164,165]. Current risk scores such as the NCDR bleeding risk-prediction model and the simplified NCDR bleeding-risk score have performed modestly well in identifying patients at a high risk of periprocedural bleeding [166]. To improve the performance of the existing risk model, an ML-based model was developed on 3,316,465 patients enrolled in the CathPCI registry [167]. In addition to the 31 variables used in the existing model, 28 new variables were incorporated to devise an integrated model via the gradient-boosting approach. The blended model using ML had a higher discriminatory power than the existing model ( $C$ statistic 0.82 vs. 0.78 , $p<0.05$ ) and improved the positive predictive value to $26.6 \%$, compared with $21.5 \%$ for the existent model.

One of the primary challenges faced in the PCI era is in-stent restenosis, which is linked to neointimal proliferation due to vascular wall damage [168]. The incidence of ISR has been estimated to be $20-40 \%$ for bare metallic stents and $10-15 \%$ for drug-eluting stents $[168,169]$. Smaller vessel size, increasing stent length, complex lesion morphology, diabetes mellitus, and prior bypass surgery are risk factors for stent restenosis [169]. These factors have been incorporated with other variables to devise risk models such as PRESTO 1, PRESTO 2, and EVENT scores to provide an estimated risk of ISR [170,171]. These models have a modest discriminatory power in predicting ISR, leaving room for improvement. A big-data approach incorporated 68 variables relating to clinical, demographic, and angiographic characteristics to devise a risk prediction model for ISR [172]. The ML model, when applied post-PCI, achieved a higher discriminatory power (AUC for the precision recall curve was 0.45 vs. $0.31,0.27$, and 0.18 for PRESTO-1, PRESTO-2, and EVENT, respectively, $p<0.05$ ) to predict ISR at 12 months. Interestingly, post-PCI TIMI flow was one of the prominent predictors of ISR, alongside diabetes mellitus and the presence of $\geq 2$ vessel CAD. Though the model requires external validation, given the small sample size of the population $(n=263)$, the study yet again underscores the merit of ML in identifying crucial parameters from a vast dataset to predict outcomes.

\section{Artificial Intelligence-Based Long-Term Mortality and MACE Prediction Models}

Prognostic modeling via ML has been validated with the use of electronic health records (EHRs) integrated with clinical scores and imaging modalities to predict MACE [173-175]. 
Utilizing the array of data available in EMR and identifying patterns based on clinical course, ML models have been used to create a personalized treatment algorithm (ML4CAD) for every patient, based on risk factors, past medical history, time present in the EMR system, and medications. The illustrated model makes clinical decisions for patients based on these factors and suggests a decision with an aim to increase prescription effectiveness, evaluated in the terms of time from initial diagnosis to the first potential adverse event (time to adverse event, TAE). The model had superior performance when compared to standard of care, increasing the time to adverse event (TAE) from 4.56 to 5.66 years ( $24.3 \%$ increase), hence furthering the idea of precision medicine [174,176].

Imaging findings, such as CAC score quantified from cardiac computed tomography, are an independent risk factor adding to the traditional clinical risk factors in predicting longterm risk of cardiovascular events [177-179]. Noncontrast CT imaging, other than providing information on the CAC score, provides valuable measures such as epicardial adipose tissue (EAT) volume, and EAT attenuation, all of which have been shown to provide additional information regarding the long-term risk of cardiovascular disease [180-182]. Extracting these pieces of data can be tedious and labor-intensive, and automated techniques can result in more standardized evaluations in a more time-efficient manner.

Multiple ML techniques have been proposed to automatically evaluate CAC score from dedicated cardiac and non-EKG gated chest CT scans [66,67,183-185]. ML techniques incorporating CAC score and other imaging parameters have been shown to be a better predictor than the traditional risk scores employed for cardiovascular disease risk stratification [181,186-189]. An ensemble-boosting model developed by Nakanishi et al. incorporating a total of 77 clinical and imaging variables had a superior discriminatory power for predicting coronary heart disease deaths than imaging and clinical data alone (AUC for ML model: 0.845 compared to 0.821 and 0.781 for clinical data and CAC respectively, $p<0.001$ ) (Figure 5) [190].

Apart from CAC scoring and traditional CT metrics, the role of EAT volume and attenuation in the prediction of future cardiovascular risk has been an active area of research. Deep-learning approaches to automatically compute EAT volume and EAT attenuation from CT have been developed, significantly reducing generation time from $15 \mathrm{~min}$ to $2 \mathrm{~s}$ [186]. Eisenberg et al. demonstrated an independent association between deep-learningderived EAT volume and attenuation with the risk of future MACE, defined as myocardial infarction, late ( $>180$ days) revascularization, and cardiac death (HR:1.35, $p<0.01$ and 0.83, $p=0.01$, demonstrating a direct correlation with EAT volume and an inverse correlation with EAT attenuation respectively) [187]. Subsequently, these parameters have been combined with other physiologic and radiology variables to develop new deep-learning approaches, which have further been shown to have a higher predictive value than the traditional risk scores $[186,189]$. These have been summarized in Table 2.

Apart from its role in CAD diagnosis, CCTA has been shown to have an incremental prognostic value in terms of short- and long-term risk prediction. Results from the CONFIRM registry validated two CCTA parameters, namely the number of proximal segments with stenosis $>50 \%$ and the number of proximal segments with mixed or calcified plaque as important prognostic markers above the predictive value of the Framingham risk score (FRS) [191-193]. 


\section{Variable ranking for prediction of $\mathrm{CHD}$ death}
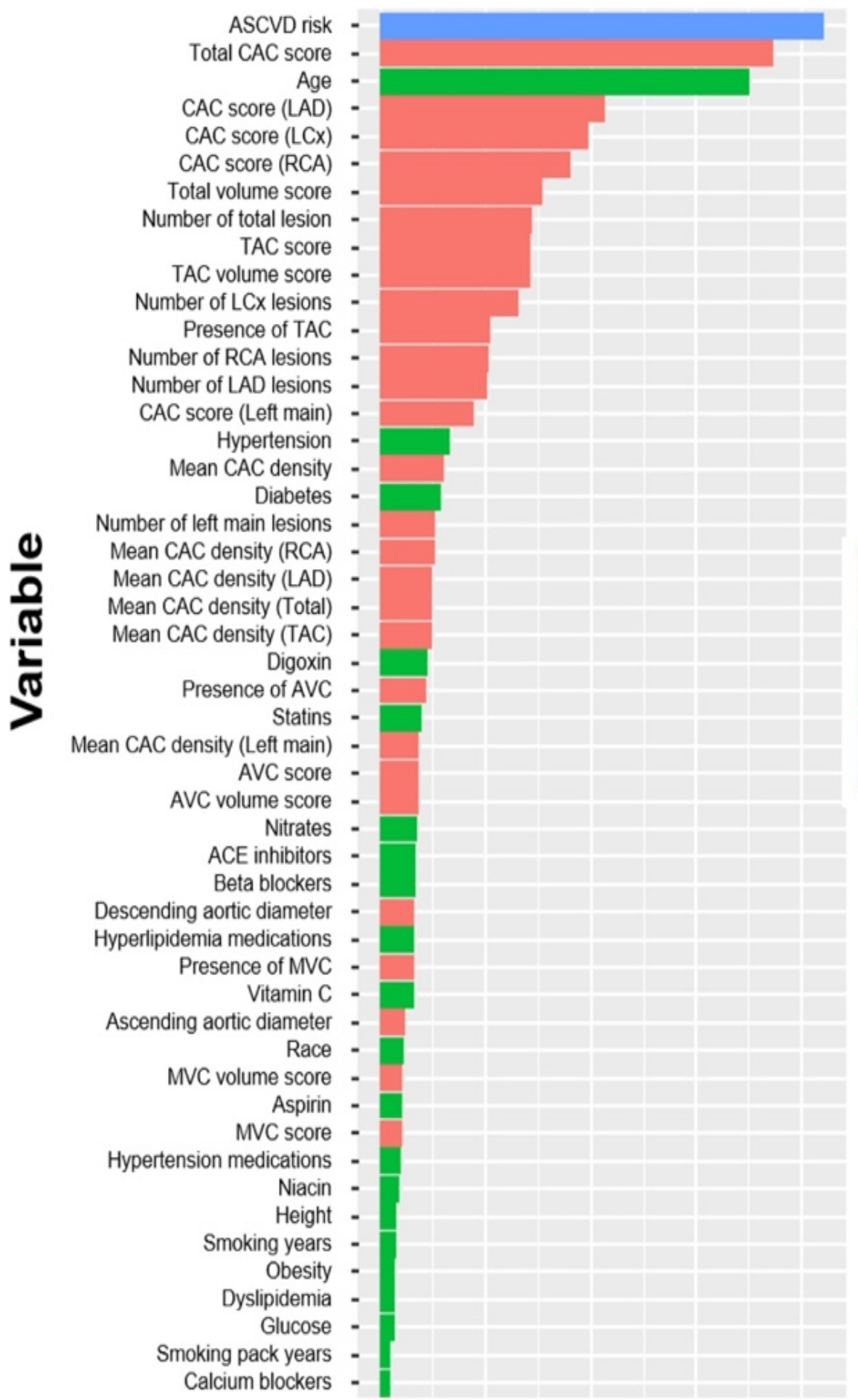

Mean CAC density (LAD) -

Mean CAC density (Total) -

Mean CAC density (TAC)

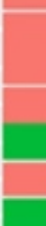

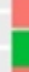


Table 2. Studies evaluating the impact of coronary artery calcium score (CACS) among other variables in the prediction of mortality in patients with no history of coronary artery disease.

\begin{tabular}{|c|c|c|c|c|c|}
\hline Study & Study Design/Sample Size & ML Model & Brief Description and Follow-Up & Results & Limitations \\
\hline $\begin{array}{l}\text { Eisenberg et al. [187] } \\
\qquad 2020\end{array}$ & $\begin{array}{l}\text { Prospective single-center study, } \\
2068 \text { asymptomatic patients }\end{array}$ & Convolutional neural network & $\begin{array}{l}\text { To check for impact of EAT volume } \\
\text { and EAT attenuation computed via } \\
\text { deep learning in prediction of MACE, } \\
\text { defined as defined as MI, late }(>180 \\
\text { days) revascularization and } \\
\text { cardiac death. } \\
\text { Follow up: }>14 \text { years }\end{array}$ & $\begin{array}{l}\text { Increased EAT volume (HR: 1.35) and } \\
\text { decreased EAT attenuation (HR 0.83) } \\
\text { independently associated with } \\
\text { MACE in addition to CACS (HR 1.25) } \\
\text { and ASCVD score (HR 1.03), } p<0.01 \\
\text { for all. }\end{array}$ & $\begin{array}{ll}\text { 1. } & \text { Study done on asymptomatic } \\
\text { patients; external validation } \\
\text { needed if applied on } \\
\text { symptomatic patients. } \\
\text { 2. } \\
\text { Previous-generation CT } \\
\text { scanners used (data collected } \\
\text { from 1998-2005). }\end{array}$ \\
\hline $\begin{array}{l}\text { Han et al. [188] } \\
2020\end{array}$ & $\begin{array}{l}\text { Retrospective multicenter study, } \\
86,155 \text { asymptomatic patients }\end{array}$ & Boosted ensemble & $\begin{array}{l}\text { ML model with } 35 \text { clinical, } 32 \text { lab, } \\
\text { and } 3 \text { CACS parameters (CACS, } \\
\text { calcium volume, and calcium mass) } \\
\text { in prediction of all-cause mortality } \\
\text { Median follow up: } 4.6 \text { years }\end{array}$ & $\begin{array}{l}\text { ML }(0.82)>\text { ASCVD score + CACS } \\
(0.74)>\text { Framingham risk score }+ \\
\text { CACS (0.70)-reported as AUC in the } \\
\text { test set. } \\
\text { No statistical difference in the } \\
\text { performance in the validation set. }\end{array}$ & $\begin{array}{l}\text { Retrospective } \\
\text { All-cause mortality reported } \\
\text { rather than specific } \\
\text { cardiac endpoints. }\end{array}$ \\
\hline $\begin{array}{c}\text { Nakanishi et al. [190] } \\
2021\end{array}$ & $\begin{array}{l}\text { Multicenter observational study, } \\
66,636 \text { asymptomatic patients }\end{array}$ & Boosted ensemble (Logitboost) & $\begin{array}{l}\text { ML model incorporating } 46 \text { clinical } \\
\text { and } 31 \text { CT variables-CAC score, } \\
\text { extra coronary scores (not including } \\
\text { EAT) in prediction of cardiovascular } \\
\text { (CHD + stroke }+ \text { CHF + other } \\
\text { circulatory diseases), and coronary } \\
\text { heart disease (CHD) deaths } \\
\text { Follow up: } 10 \text { years }\end{array}$ & $\begin{array}{ll}\text { 1. } & \text { For cardiovascular deaths: } \\
\text { AUC for ML (all) } 0.8445 & > \\
\text { ASCVD (0.821) > CAC } \\
\text { score }(0.78) \text {. } \\
\text { 2. For coronary heart disease } \\
\text { deaths: AUC for ML (all) } 0.860 \\
\text { > ASCVD (0.835) > CAC } \\
\text { score }(0.816) .\end{array}$ & $\begin{array}{l}\text { Multiple CT variables, } \\
\text { including EAT, were not } \\
\text { available for some patients. }\end{array}$ \\
\hline $\begin{array}{l}\text { Tamarappoo et al. [189] } \\
2021\end{array}$ & $\begin{array}{l}\text { Prospective single-center study, } \\
1069 \text { asymptomatic patients }\end{array}$ & Boosted ensemble (XgBoost) & $\begin{array}{l}\text { ML model using } 12 \text { variables from } \\
\text { ASCVD score, } 5 \text { CT parameters } \\
\text { (including EAT volume and } \\
\text { attenuation) and top } 15 \text { serum } \\
\text { biomarkers) to predict cardiac events } \\
\text { Mean follow up: } 14.5 \text { years }\end{array}$ & $\begin{array}{l}\text { ML }(0.81)>\text { CAC }(0.75)>\text { ASCVD } \\
(0.74) .\end{array}$ & $\begin{array}{l}\text { Single-center study } \\
\text { Overfitting; given the small } \\
\text { number of cardiac events } \\
\text { during follow up }(\sim 2 \%)\end{array}$ \\
\hline
\end{tabular}

ASCVD: atherosclerotic cardiovascular disease; CHF: congestive heart failure; EAT: epicardial adipose tissue; HR: hazard ratio; MI: myocardial infarction. 
A multitude of ML approaches have been described, combining imaging parameters with clinical and demographic parameters for better prognostication of cardiovascular outcomes [194-199] Including 10,030 patients with suspected CAD from the CONFIRM registry, Motwani et al. utilized a boosting ensemble algorithm using 25 clinical and 44 CCTA parameters [195]. The ML algorithm performed better in predicting 5-year allcause mortality than CCTA segment stenosis score or FRS (AUC 0.79 for ML vs. 0.664 for segment stenosis score and 0.61 for FRS, respectively, $p<0.001$ ). More recently, models incorporating high-risk plaque features with the traditional imaging and clinical parameters have performed better than either of the parameters in isolation [196,197]. A review of literature summarizing all the studies is presented in Table 3.

Although anatomical CT scores and plaque features provide useful diagnostic and prognostic data, the complex interplay of factors at the molecular level, in addition to patient-level characteristics leading to specific phenotypic manifestations in terms of plaque burden and features, is not well-elucidated and remains an area of active research. In particular, elucidating important factors that "drive" the process of atherosclerotic plaque formation and progression is not only vital from a therapeutic perspective, but it can also improve risk-assessment strategies. Recent studies have demonstrated that coronary artery inflammation inhibits lipid accumulation in the perivascular adipose tissue [200]. This results in a higher attenuation of the affected perivascular area, identified on CCTA as the fat attenuation index (FAI). FAI has been shown to be a sensitive marker of coronary inflammation, with higher FAI values $(\geq-70.1 \mathrm{HU})$ independently predicting cardiovascular mortality [200,201]. A posthoc analysis of the CRISP-CT study showed an incremental value of adding FAI to high-risk plaque characteristics, pointing towards a more significant role of these precursor lesions in predicting patient outcomes [202]. A more recent ML approach created a pericoronary fat 'radiomic' profile (FRP), identifying radiomic variables predicting tissue inflammation, fibrosis, and vascularity on CCTA [203]. The incorporation of FRP significantly improved the MACE predictive ability of the traditional model (AUC for traditional + FRP 0.88 vs. 0.754 for the traditional model, $p<0.001$ ). Using a cut-off of 0.63 , individuals in the high FRP group were at a higher risk of MACE $(\mathrm{HR}=10.84, p<0.001)$. Importantly, Kaplan-Meir analysis showed an additional value of FRP over high-risk plaque (HRP) characteristics in predicting long-term survival (HR for the FRP-/HRP+ subgroup 5.97, $p=0.03$ compared to 43.33 for the FRP+/HRP+ subgroup). Such 'radiotranscriptomic' approaches incorporating molecular biology and radiology and evaluating their interaction via artificial intelligence can help uncover deeper relationships between metabolic pathways and clinical outcomes, helping to better understand the pathophysiology and elements involved in the clinical progression of cardiovascular disease. 
Table 3. Summary of literature regarding mortality outcomes using CCTA data.

\begin{tabular}{|c|c|c|c|c|c|}
\hline Study & Study Design/Sample Size & ML & Brief Description and Outcomes & Results & Limitations \\
\hline $\begin{array}{l}\text { Motwani et al. [195] } \\
2016\end{array}$ & $\begin{array}{l}\text { Multicenter prospective study, } \\
10,030 \text { patients with } \\
\text { suspected CAD }\end{array}$ & Boosted ensemble (LogitBoost) & $\begin{array}{l}25 \text { clinical and } 44 \text { CCTA parameter used } \\
\text { to create ML model } \\
\text { Outcome: Prediction of 5-year ACM; } \\
\text { compared against clinical risk scores and } \\
\text { CCTA parameters. }\end{array}$ & $\begin{array}{l}\text { AUC: ML }(0.79)>\text { Segment stenosis score } \\
\text { (SSS) (0.64) and FRS }(0.61) ; p<0.001 .\end{array}$ & $\begin{array}{l}\text { Observational; concern for } \\
\text { selection bias } \\
\text { Cardiac-specific endpoints were } \\
\text { not defined, given the } \\
\text { data unavailability. }\end{array}$ \\
\hline \multirow[b]{2}{*}{$\begin{array}{l}\text { Hoshino et al. [198] } \\
\quad 2016\end{array}$} & \multirow[b]{2}{*}{$\begin{array}{l}\text { Multicenter retrospective study, } \\
220 \text { patients with intermediate } \\
\text { LAD stenosis }\end{array}$} & \multirow[b]{2}{*}{$\begin{array}{c}\text { Unsupervised } \\
\text { hierarchical clustering }\end{array}$} & $\begin{array}{l}\text { Two clusters (CS1 and CS2) using } 42 \\
\text { variables created via ML. } \\
\text { Outcome: }\end{array}$ & $\begin{array}{l}\text { Age, CS1 features (higher plaque } \\
\text { volume, remodeling index, higher }\end{array}$ & $\begin{array}{l}\text { Retrospective, small size } \\
\text { Majority of vessels were LAD; } \\
\text { hence the study was restricted to a }\end{array}$ \\
\hline & & & $\begin{array}{l}\text { Relation between FAI and CCTA } \\
\text { defined clusters, } \\
\text { 2. }\end{array}$ & $\begin{array}{l}\text { FAI amongst others), and FAI were } \\
\text { independent predictors of MACE. } \\
\text { Improved NRI with (FRS + CS1 + } \\
\text { FAI) as compared to FRS alone. }\end{array}$ & $\begin{array}{l}\text { hence the study was restricted to a } \\
\text { specific population. } \\
40 \% \text { cardiac events were non-LAD } \\
\text { revascularization; hence the results } \\
\text { were not generalizable. }\end{array}$ \\
\hline $\begin{array}{l}\text { Van Rosendael et al. [197] } \\
2018\end{array}$ & $\begin{array}{l}\text { Multicenter prospective study, } \\
8844 \text { patients with } \\
\text { suspected CAD }\end{array}$ & Boosted ensemble & $\begin{array}{l}35 \text { variables (SS and plaque composition } \\
\text { for } 16 \text { coronary segments and } 3 \text { additional } \\
\text { variables) compared with traditional } \\
\text { CT scores. } \\
\text { Outcome: ML vs. traditional CT scores in } \\
\text { predicting 5-year composite MI and death. }\end{array}$ & AUC for ML $(0.77)>$ SSS $(0.70)$ & $\begin{array}{l}\text { No comparison with clinical } \\
\text { risk scores } \\
\text { Retrospective study with risk of } \\
\text { selection bias }\end{array}$ \\
\hline $\begin{array}{l}\text { Johnson et al. [194] } \\
2019\end{array}$ & $\begin{array}{l}\text { Single-center retrospective study, } \\
6892 \text { patients }\end{array}$ & K nearest neighbors & $\begin{array}{l}\text { ML model ( } 64 \text { vessel-related features) vs. } \\
\text { CAD-RADS. } \\
\text { Outcome: Prediction of ACM, } \\
\text { CAD-related deaths. Also, decision to } \\
\text { start statin. }\end{array}$ & $\begin{array}{ll}\text { 1. } & \text { AUC for all-cause mortality } \\
\text { (0.77) > CAD-RADS (0.72); AUC for } \\
\text { CAD-related deaths-ML }-\mathrm{ML} \\
\text { (0.85) > CAD-RADS (0.79). } \\
\text { 2. } \\
\text { Significant increase in sensitivity } \\
\text { with ML model. }\end{array}$ & $\begin{array}{l}\text { Retrospective study with limited } \\
\text { population diversity } \\
\text { Unblinded CCTA results that might } \\
\text { have affected event incidence }\end{array}$ \\
\hline $\begin{array}{l}\text { Johnson et al. [199] } \\
\quad 2020\end{array}$ & $\begin{array}{l}\text { Single-center retrospective study, } \\
6892 \text { patients }\end{array}$ & & $\begin{array}{l}\text { ML model developed via } \\
\text { radiologist report. } \\
\text { Outcome: Prediction of ACM and } \\
\text { CAD-related mortality; compared against } \\
\text { FRS. Also, decision to start statin. }\end{array}$ & $\begin{array}{ll}\text { 1. } & \text { ACM: AUC for ML }(0.85)>\text { FRS } \\
\text { (0.79) CAD related deaths: AUC for } \\
\text { ML (0.87) > FRS (0.82) } \\
\text { 2. } \\
\text { Using ML, equally high sensitivity } \\
\text { but significant reduction in } \\
\text { unnecessary statin prescription } \\
\text { (AUC for ML 0.89 vs. FRS } 0.75 \text { ). }\end{array}$ & $\begin{array}{l}\text { Retrospective study design } \\
\text { Concern for misclassification bias } \\
\text { due to incomplete follow-up }\end{array}$ \\
\hline $\begin{array}{l}\text { Tesche et al. [196] } \\
\qquad 2021\end{array}$ & $\begin{array}{l}\text { Single-center retrospective study, } \\
361 \text { patients with suspected and } \\
\text { confirmed CAD }\end{array}$ & Boosted ensemble (RUSBoost) & $\begin{array}{l}28 \text { clinical, CCTA scores and adverse } \\
\text { plaque characteristics included. } \\
\text { Outcome: } 5 \text {-year MACE prediction; } \\
\text { compared against FRS, CCTA scores and } \\
\text { adverse plaque features. }\end{array}$ & $\begin{array}{ll}\text { 1. } & \text { AUC for ML }(0.96)>\text { AS }(0.84)> \\
& \text { FRS (0.76). } \\
\text { 2. } & \text { Important imaging parameters: } \\
\text { SSS, obstructive CAD of RCA. } \\
\text { 3. } & \text { Important clinical factors: age, FRS }\end{array}$ & $\begin{array}{l}\text { Small sample size, retrospective } \\
\text { study design } \\
\text { Follow-up using medical records } \\
\text { No external validation to test } \\
\text { prognostic accuracy }\end{array}$ \\
\hline
\end{tabular}

ACM: all-cause mortality; AS: Agatston score; CAD-RADS: coronary artery disease reporting and data system; CS: cluster sample; FAI: fat attenuation index; FRS: Framingham risk score; RCA: right coronary artery; SSS: segment stenosis score. 


\section{Discussions}

With significant developments occurring in the last decade in terms of data processing and analytics, AI can provide new and sophisticated tools that could help us to better understand disease processes, which ultimately should translate into better patient care and outcomes (Figure 6). Nevertheless, AI comes with its own set of limitations. ML models lack interpretability and suffer from the 'black box' problem [204]. ML models based on neural networks and ensemble methods are inherently complex and are derived from complicated mathematical algorithms. 'Explainable (interpretable) machine learning', whereby simple approximations of the model are devised to make it more understandable, is being developed to overcome the black box problem [205,206].

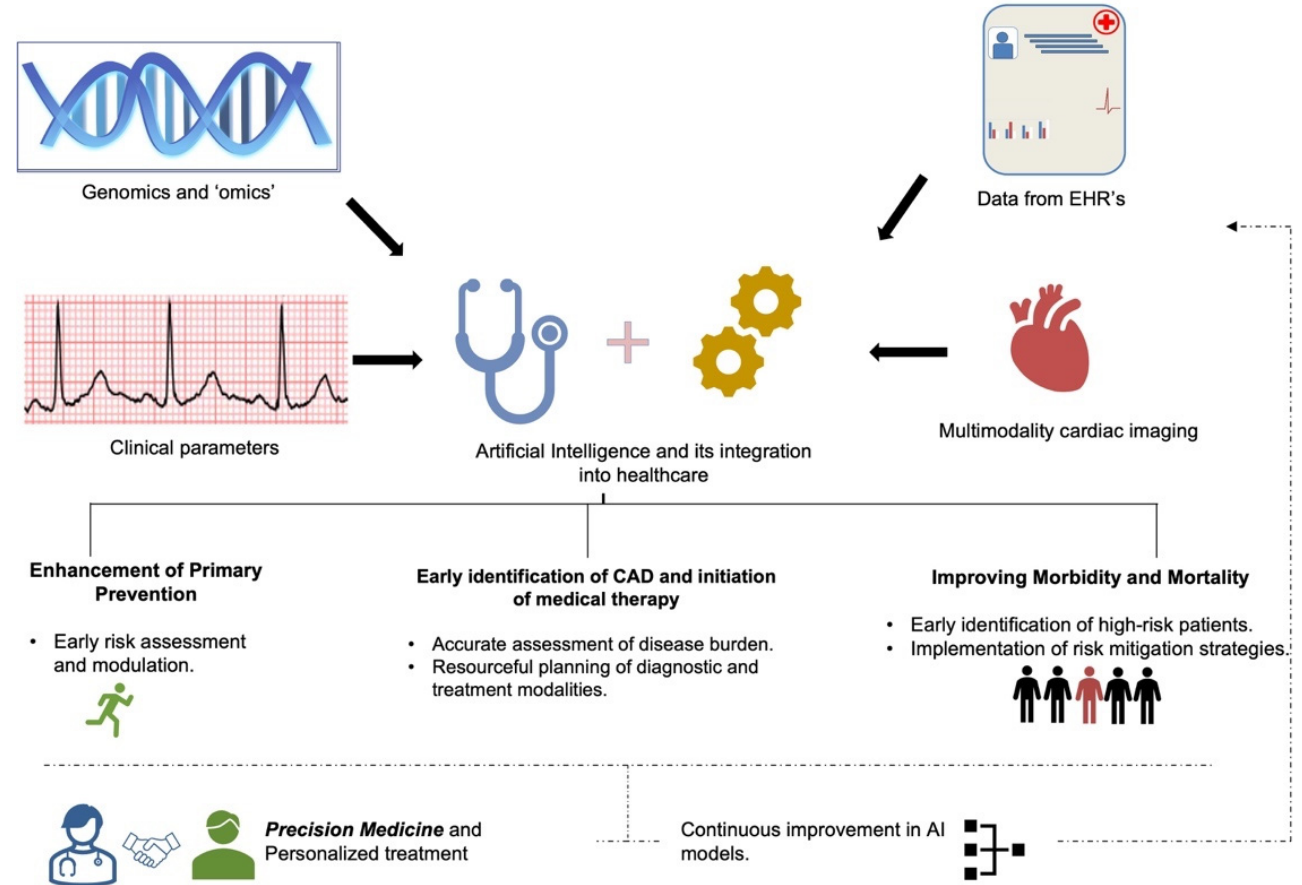

Figure 6. Current applicability and future directions for AI in coronary artery disease.

Another limitation of ML encountered at the model-development phase is sampling bias and lack of external validation $[207,208]$. ML learning models usually derive their weights from large datasets. Datasets, particularly those derived from EHRs, might be skewed and not representative of the entire population, leading to significant sampling bias and limited generalizability. A few models have tried to address this problem by stratifying the datasets at the model-development phase to ensure not to lose representation of any subgroup and preserve the model's generalizability. Nevertheless, randomized controlled trials are needed to potentially overcome this bias and establish the model performance against the standard clinical parameters. In addition, imputation methods such as MICE have been used to address the missing data issue [209].

Furthermore, the creation of bigger datasets by pooling data from multiple hospital systems has led to a lack of standardization of datasets, potentially compromising the quality of analysis. Datasets might internally differ from each other because of the different mechanisms used to generate them. For instance, one dataset might define the presence of diabetes mellitus through ICD-10 codes, while another dataset might define it using glycemic indices, such as the hemoglobin A1c. On a similar theme, ML models developed by using imaging modalities deserve a special mention. For instance, differences can exist at the level of image scanning (different scanner characteristics and vendors), image quality (radiation dose, motion artifacts), and image processing (reconstruction filters, post-processing) which can potentially lead to significant variability and differences of the assimilated data. A prerequisite to the development of any ML model is the centralization 
of data, which is tedious given the different image processing algorithms employed at various institutions. This lack of standardization needs to be addressed before AI can be fully integrated into clinical practice.

Overfitting is another concern encountered during ML model development, which occurs when the algorithm learns the data 'too well' and interprets the signal noise as concepts [210]. This usually happens with smaller datasets and can lead to a lack of external validity, despite high performance in the training and internal validation datasets. A definite solution is $\mathrm{k}$-fold cross-validation, whereby data is randomly divided into an arbitrary $k$ number of partitions. The model is trained using $k-1$ number of data subsets and tested on the remaining subset. This process is repeated $k$ total number of times, using different combinations of training and testing datasets to select the best model hyperparameters to yield the final model. This can potentially reduce noise and lead to better generalizability of the model in the overall population.

Apart from the problems encountered at the model development and training phase, there are a few noteworthy practical limitations to the implementation of ML within healthcare workflows. Firstly, unauthorized data access is an issue, as handling such large amounts of data also poses a risk of leaking sensitive patient information, thereby violating patient confidentiality and privacy [211]. Furthermore, comparisons between various machine-learning methods are difficult, given the different combinations of model parameters and different population characteristics used for in model development. Hence, it becomes difficult for physicians to compare and choose one model over the other. Prospective future trials, comparing these models on the same dataset, are needed to select the best algorithm fit for integration into routine clinical decision-making. Proper integration of AI can only be achieved once these models are embedded within EHRs. However, the full implementation and assimilation of developed AI models into EHRs can be a complex issue, as it depends on organizational resources and patient-privacy policies. Furthermore, available algorithms may be limited to off-the-shelf ML models, rather than more intricate and complex neural networks, which is easier to implement in a real clinical setting. Yet, a data-driven approach utilizing advanced analytic techniques can help clinicians and patients to make informed decisions, improve care, and optimize workflow efficiency.

\section{Conclusions}

In conclusion, AI provides an unprecedented potential to transform healthcare and enhance the current system's ability to serve populations at large, while providing tools to focus on individualized yet comprehensive and precise care.

Author Contributions: Conceptualization, S.J.A.; data curation, N.G. and P.S.; writing-original draft preparation, N.G., P.S. and A.M.; writing-review and editing, N.G., M.G.R., M.H.A.-M., G.P., Y.Z., B.C.L. and S.J.A. All authors have read and agreed to the published version of the manuscript.

Funding: This research received no external funding.

Data Availability Statement: Not applicable.

Conflicts of Interest: Subhi J. Al'Aref is supported by NIH 2R01 HL12766105 \& 1R21 EB030654 and receives royalty fees from Elsevier. Gianluca Pontone receives honorarium and institutional research funding from GE Healthcare, Bracco, Boehringer Ingelheim, Bayer, and Heartflow. Mouaz Al-Mallah receives research support from SiEMENS and consulting fee/honorarium from Philips, Pfizer, and Draximage. All other authors have reported that they have no relationships relevant to the contents of this paper to disclose. 


\section{References}

1. Virani, S.S.; Alonso, A.; Aparicio, H.J.; Benjamin, E.J.; Bittencourt, M.S.; Callaway, C.W.; Carson, A.P.; Chamberlain, A.M.; Cheng, S.; Delling, F.N.; et al. Heart Disease and Stroke Statistics-2021 Update. Circulation 2021, 143, e254-e743. [CrossRef]

2. Benjamin, E.J.; Muntner, P.; Alonso, A.; Bittencourt, M.S.; Callaway, C.W.; Carson, A.P.; Chamberlain, A.M.; Chang, A.R.; Cheng, S.; Das, S.R.; et al. Heart Disease and Stroke Statistics-2019 Update: A Report From the American Heart Association. Circulation 2019, 139, e56-e528. [CrossRef]

3. Arnett, D.K.; Blumenthal, R.S.; Albert, M.A.; Buroker, A.B.; Goldberger, Z.D.; Hahn, E.J.; Himmelfarb, C.D.; Khera, A.; Lloyd-Jones, D.; McEvoy, J.W.; et al. 2019 ACC/AHA Guideline on the Primary Prevention of Cardiovascular Disease: A Report of the American College of Cardiology/American Heart Association Task Force on Clinical Practice Guidelines. Circulation 2019, 140, e596-e646. [CrossRef]

4. Aragam, K.G.; Natarajan, P. Polygenic Scores to Assess Atherosclerotic Cardiovascular Disease Risk: Clinical Perspectives and Basic Implications. Circ. Res. 2020, 126, 1159-1177. [CrossRef]

5. Schaap, J.; de Groot, J.A.H.; Nieman, K.; Meijboom, W.B.; Boekholdt, S.M.; Kauling, R.M.; Post, M.C.; Van der Heyden, J.A.; de Kroon, T.L.; Rensing, B.J.W.M.; et al. Added value of hybrid myocardial perfusion SPECT and CT coronary angiography in the diagnosis of coronary artery disease. Eur. Heart J.-Cardiovasc. Imaging 2014, 15, 1281-1288. [CrossRef]

6. Andreini, D.; Magnoni, M.; Conte, E.; Masson, S.; Mushtaq, S.; Berti, S.; Canestrari, M.; Casolo, G.; Gabrielli, D.; Latini, R.; et al. Coronary Plaque Features on CTA Can Identify Patients at Increased Risk of Cardiovascular Events. JACC Cardiovasc. Imaging 2020, 13, 1704-1717. [CrossRef]

7. Budoff, M.J.; Mayrhofer, T.; Ferencik, M.; Bittner, D.; Lee, K.L.; Lu, M.T.; Coles, A.; Jang, J.; Krishnam, M.; Douglas, P.S.; et al. Prognostic Value of Coronary Artery Calcium in the PROMISE Study (Prospective Multicenter Imaging Study for Evaluation of Chest Pain). Circulation 2017, 136, 1993-2005. [CrossRef]

8. Patel, V.L.; Shortliffe, E.H.; Stefanelli, M.; Szolovits, P.; Berthold, M.R.; Bellazzi, R.; Abu-Hanna, A. The coming of age of artificial intelligence in medicine. Artif. Intell. Med. 2009, 46, 5-17. [CrossRef]

9. Ranka, S.; Reddy, M.; Noheria, A. Artificial intelligence in cardiovascular medicine. Curr. Opin. Cardiol. 2021, 36, 26-35. [CrossRef]

10. Dey, D.; Slomka, P.J.; Leeson, P.; Comaniciu, D.; Shrestha, S.; Sengupta, P.P.; Marwick, T.H. Artificial Intelligence in Cardiovascular Imaging: JACC State-of-the-Art Review. J. Am. Coll. Cardiol. 2019, 73, 1317-1335. [CrossRef]

11. Johnson, K.W.; Torres Soto, J.; Glicksberg, B.S.; Shameer, K.; Miotto, R.; Ali, M.; Ashley, E.; Dudley, J.T. Artificial Intelligence in Cardiology. J. Am. Coll. Cardiol. 2018, 71, 2668-2679. [CrossRef] [PubMed]

12. Sprangers, M.A.G.; Sloan, J.A.; Barsevick, A.; Chauhan, C.; Dueck, A.C.; Raat, H.; Shi, Q.; Van Noorden, C.J.F.; Consortium, G. Scientific imperatives, clinical implications, and theoretical underpinnings for the investigation of the relationship between genetic variables and patient-reported quality-of-life outcomes. Qual. Life Res. 2010, 19, 1395-1403. [CrossRef] [PubMed]

13. Erdmann, J.; Kessler, T.; Munoz Venegas, L.; Schunkert, H. A decade of genome-wide association studies for coronary artery disease: The challenges ahead. Cardiovasc. Res. 2018, 114, 1241-1257. [CrossRef] [PubMed]

14. Noll, D.R.; Ginsberg, T.; Elahi, A.; Cavalieri, T.A. Effective Patient-Physician Communication Based on Osteopathic Philosophy in Caring for Elderly Patients. J. Osteopath. Med. 2016, 116, 42-47. [CrossRef]

15. Kathiresan, S.; Melander, O.; Anevski, D.; Guiducci, C.; Burtt, N.P.; Roos, C.; Hirschhorn, J.N.; Berglund, G.; Hedblad, B.; Groop, L.; et al. Polymorphisms associated with cholesterol and risk of cardiovascular events. N. Engl. J. Med. 2008, 358, 1240-1249. [CrossRef]

16. Brautbar, A.; Pompeii, L.A.; Dehghan, A.; Ngwa, J.S.; Nambi, V.; Virani, S.S.; Rivadeneira, F.; Uitterlinden, A.G.; Hofman, A.; Witteman, J.C.; et al. A genetic risk score based on direct associations with coronary heart disease improves coronary heart disease risk prediction in the Atherosclerosis Risk in Communities (ARIC), but not in the Rotterdam and Framingham Offspring, Studies. Atherosclerosis 2012, 223, 421-426. [CrossRef]

17. Eraslan, G.; Avsec, Ž.; Gagneur, J.; Theis, F.J. Deep learning: New computational modelling techniques for genomics. Nat. Rev. Genet. 2019, 20, 389-403. [CrossRef]

18. Wang, Y.; Liu, T.; Liu, Y.; Chen, J.; Xin, B.; Wu, M.; Cui, W. Coronary artery disease associated specific modules and feature genes revealed by integrative methods of WGCNA, MetaDE and machine learning. Gene 2019, 710, 122-130. [CrossRef]

19. Balashanmugam, M.V.; Shivanandappa, T.B.; Nagarethinam, S.; Vastrad, B.; Vastrad, C. Analysis of Differentially Expressed Genes in Coronary Artery Disease by Integrated Microarray Analysis. Biomolecules 2019, 10, 35. [CrossRef]

20. Zhang, D.; Guan, L.; Li, X. Bioinformatics analysis identifies potential diagnostic signatures for coronary artery disease. J. Int. Med. Res. 2020, 48, 300060520979856. [CrossRef]

21. Dogan, M.V.; Grumbach, I.M.; Michaelson, J.J.; Philibert, R.A. Integrated genetic and epigenetic prediction of coronary heart disease in the Framingham Heart Study. PLoS ONE 2018, 13, e0190549. [CrossRef]

22. Pattarabanjird, T.; Cress, C.; Nguyen, A.; Taylor, A.; Bekiranov, S.; McNamara, C. A Machine Learning Model Utilizing a Novel SNP Shows Enhanced Prediction of Coronary Artery Disease Severity. Genes 2020, 11, 1446. [CrossRef]

23. Naushad, S.M.; Hussain, T.; Indumathi, B.; Samreen, K.; Alrokayan, S.A.; Kutala, V.K. Machine learning algorithm-based risk prediction model of coronary artery disease. Mol. Biol. Rep. 2018, 45, 901-910. [CrossRef]

24. Ferguson, J.F.; Matthews, G.J.; Townsend, R.R.; Raj, D.S.; Kanetsky, P.A.; Budoff, M.; Fischer, M.J.; Rosas, S.E.; Kanthety, R.; Rahman, M.; et al. Candidate gene association study of coronary artery calcification in chronic kidney disease: Findings from the CRIC study (Chronic Renal Insufficiency Cohort). J. Am. Coll. Cardiol. 2013, 62, 789-798. [CrossRef] 
25. O’Donnell, C.J.; Kavousi, M.; Smith, A.V.; Kardia, S.L.; Feitosa, M.F.; Hwang, S.J.; Sun, Y.V.; Province, M.A.; Aspelund, T.; Dehghan, A.; et al. Genome-wide association study for coronary artery calcification with follow-up in myocardial infarction. Circulation 2011, 124, 2855-2864. [CrossRef]

26. Oguz, C.; Sen, S.K.; Davis, A.R.; Fu, Y.P.; O'Donnell, C.J.; Gibbons, G.H. Genotype-driven identification of a molecular network predictive of advanced coronary calcium in ClinSeq ${ }^{\circledR}$ and Framingham Heart Study cohorts. BMC Syst. Biol. 2017, 11, 99. [CrossRef]

27. Diamond, G.A.; Forrester, J.S. Analysis of probability as an aid in the clinical diagnosis of coronary-artery disease. N. Engl. J. Med. 1979, 300, 1350-1358. [CrossRef]

28. Foldyna, B.; Udelson, J.E.; Karády, J.; Banerji, D.; Lu, M.T.; Mayrhofer, T.; Bittner, D.O.; Meyersohn, N.M.; Emami, H.; Genders, T.S.S.; et al. Pretest probability for patients with suspected obstructive coronary artery disease: Re-evaluating Diamond-Forrester for the contemporary era and clinical implications: Insights from the PROMISE trial. Eur. Heart J. Cardiovasc. Imaging 2019, 20, 574-581. [CrossRef]

29. Genders, T.S.; Steyerberg, E.W.; Alkadhi, H.; Leschka, S.; Desbiolles, L.; Nieman, K.; Galema, T.W.; Meijboom, W.B.; Mollet, N.R.; de Feyter, P.J.; et al. A clinical prediction rule for the diagnosis of coronary artery disease: Validation, updating, and extension. Eur. Heart J. 2011, 32, 1316-1330. [CrossRef]

30. Genders, T.S.; Steyerberg, E.W.; Hunink, M.G.; Nieman, K.; Galema, T.W.; Mollet, N.R.; de Feyter, P.J.; Krestin, G.P.; Alkadhi, H.; Leschka, S.; et al. Prediction model to estimate presence of coronary artery disease: Retrospective pooled analysis of existing cohorts. BMJ 2012, 344, e3485. [CrossRef]

31. Bittencourt, M.S.; Hulten, E.; Polonsky, T.S.; Hoffman, U.; Nasir, K.; Abbara, S.; Di Carli, M.; Blankstein, R. European Society of Cardiology-Recommended Coronary Artery Disease Consortium Pretest Probability Scores More Accurately Predict Obstructive Coronary Disease and Cardiovascular Events Than the Diamond and Forrester Score: The Partners Registry. Circulation 2016, 134, 201-211. [CrossRef] [PubMed]

32. Li, D.; Xiong, G.; Zeng, H.; Zhou, Q.; Jiang, J.; Guo, X. Machine learning-aided risk stratification system for the prediction of coronary artery disease. Int. J. Cardiol. 2021, 326, 30-34. [CrossRef] [PubMed]

33. Velusamy, D.; Ramasamy, K. Ensemble of heterogeneous classifiers for diagnosis and prediction of coronary artery disease with reduced feature subset. Comput. Methods Programs Biomed. 2021, 198, 105770. [CrossRef] [PubMed]

34. Muhammad, L.J.; Al-Shourbaji, I.; Haruna, A.A.; Mohammed, I.A.; Ahmad, A.; Jibrin, M.B. Machine Learning Predictive Models for Coronary Artery Disease. SN Comput. Sci. 2021, 2, 350. [CrossRef]

35. Lin, S.; Li, Z.; Fu, B.; Chen, S.; Li, X.; Wang, Y.; Wang, X.; Lv, B.; Xu, B.; Song, X.; et al. Feasibility of using deep learning to detect coronary artery disease based on facial photo. Eur. Heart J. 2020, 41, 4400-4411. [CrossRef]

36. Gulati, M.; Levy, P.D.; Mukherjee, D.; Amsterdam, E.; Bhatt, D.L.; Birtcher, K.K.; Blankstein, R.; Boyd, J.; Bullock-Palmer, R.P.; Conejo, T.; et al. 2021 AHA/ACC/ASE/CHEST/SAEM/SCCT/SCMR Guideline for the Evaluation and Diagnosis of Chest Pain: A Report of the American College of Cardiology/American Heart Association Joint Committee on Clinical Practice Guidelines. Circulation 2021, 78, e187-e285. [CrossRef]

37. Baskaran, L.; Ying, X.; Xu, Z.; Al’Aref, S.J.; Lee, B.C.; Lee, S.E.; Danad, I.; Park, H.B.; Bathina, R.; Baggiano, A.; et al. Machine learning insight into the role of imaging and clinical variables for the prediction of obstructive coronary artery disease and revascularization: An exploratory analysis of the CONSERVE study. PLoS ONE 2020, 15, e0233791. [CrossRef]

38. Al'Aref, S.J.; Maliakal, G.; Singh, G.; van Rosendael, A.R.; Ma, X.; Xu, Z.; Alawamlh, O.A.H.; Lee, B.; Pandey, M.; Achenbach, S.; et al. Machine learning of clinical variables and coronary artery calcium scoring for the prediction of obstructive coronary artery disease on coronary computed tomography angiography: Analysis from the CONFIRM registry. Eur. Heart J. 2020, 41, 359-367. [CrossRef]

39. Arsanjani, R.; Xu, Y.; Dey, D.; Fish, M.; Dorbala, S.; Hayes, S.; Berman, D.; Germano, G.; Slomka, P. Improved accuracy of myocardial perfusion SPECT for the detection of coronary artery disease using a support vector machine algorithm. J. Nucl. Med. 2013, 54, 549-555. [CrossRef]

40. Betancur, J.; Hu, L.H.; Commandeur, F.; Sharir, T.; Einstein, A.J.; Fish, M.B.; Ruddy, T.D.; Kaufmann, P.A.; Sinusas, A.J.; Miller, E.J.; et al. Deep Learning Analysis of Upright-Supine High-Efficiency SPECT Myocardial Perfusion Imaging for Prediction of Obstructive Coronary Artery Disease: A Multicenter Study. J. Nucl. Med. 2019, 60, 664-670. [CrossRef]

41. Guner, L.A.; Karabacak, N.I.; Akdemir, O.U.; Karagoz, P.S.; Kocaman, S.A.; Cengel, A.; Unlu, M. An open-source framework of neural networks for diagnosis of coronary artery disease from myocardial perfusion SPECT. J. Nucl. Cardiol. 2010, 17, 405-413. [CrossRef]

42. Rahmani, R.; Niazi, P.; Naseri, M.; Neishabouri, M.; Farzanefar, S.; Eftekhari, M.; Derakhshan, F.; Mollazadeh, R.; Meysami, A.; Abbasi, M. Improved diagnostic accuracy for myocardial perfusion imaging using artificial neural networks on different input variables including clinical and quantification data. Rev. Esp. Med. Nucl. E Imagen. Mol. 2019, 38, 275-279. [CrossRef]

43. Betancur, J.; Commandeur, F.; Motlagh, M.; Sharir, T.; Einstein, A.J.; Bokhari, S.; Fish, M.B.; Ruddy, T.D.; Kaufmann, P.; Sinusas, A.J.; et al. Deep Learning for Prediction of Obstructive Disease From Fast Myocardial Perfusion SPECT: A Multicenter Study. JACC Cardiovasc. Imaging 2018, 11, 1654-1663. [CrossRef]

44. Arsanjani, R.; Xu, Y.; Dey, D.; Vahistha, V.; Shalev, A.; Nakanishi, R.; Hayes, S.; Fish, M.; Berman, D.; Germano, G.; et al. Improved accuracy of myocardial perfusion SPECT for detection of coronary artery disease by machine learning in a large population. $J$. Nucl. Cardiol. 2013, 20, 553-562. [CrossRef] 
45. Rabbat, M.G.; Ramchandani, S.; Sanders, W.E., Jr. Cardiac Phase Space Analysis: Assessing Coronary Artery Disease Utilizing Artificial Intelligence. Biomed. Res. Int. 2021, 2021, 6637039. [CrossRef]

46. Stuckey, T.D.; Gammon, R.S.; Goswami, R.; Depta, J.P.; Steuter, J.A.; Meine, F.J., 3rd; Roberts, M.C.; Singh, N.; Ramchandani, S.; Burton, T.; et al. Cardiac Phase Space Tomography: A novel method of assessing coronary artery disease utilizing machine learning. PLoS ONE 2018, 13, e0198603. [CrossRef]

47. Medina, R.; Panidis, I.P.; Morganroth, J.; Kotler, M.N.; Mintz, G.S. The value of echocardiographic regional wall motion abnormalities in detecting coronary artery disease in patients with or without a dilated left ventricle. Am. Heart J. 1985, 109, 799-803. [CrossRef]

48. Kusunose, K.; Abe, T.; Haga, A.; Fukuda, D.; Yamada, H.; Harada, M.; Sata, M. A Deep Learning Approach for Assessment of Regional Wall Motion Abnormality From Echocardiographic Images. JACC Cardiovasc. Imaging 2020, 13, 374-381. [CrossRef]

49. Huang, M.-S.; Wang, C.-S.; Chiang, J.-H.; Liu, P.-Y.; Tsai, W.-C. Automated Recognition of Regional Wall Motion Abnormalities Through Deep Neural Network Interpretation of Transthoracic Echocardiography. Circulation 2020, 142, 1510-1520. [CrossRef]

50. Asch, F.M.; Poilvert, N.; Abraham, T.; Jankowski, M.; Cleve, J.; Adams, M.; Romano, N.; Hong, H.; Mor-Avi, V.; Martin, R.P.; et al. Automated Echocardiographic Quantification of Left Ventricular Ejection Fraction Without Volume Measurements Using a Machine Learning Algorithm Mimicking a Human Expert. Circ. Cardiovasc. Imaging 2019, 12, e009303. [CrossRef]

51. Kwon, J.M.; Lee, S.Y.; Jeon, K.H.; Lee, Y.; Kim, K.H.; Park, J.; Oh, B.H.; Lee, M.M. Deep Learning-Based Algorithm for Detecting Aortic Stenosis Using Electrocardiography. J. Am. Heart Assoc. 2020, 9, e014717. [CrossRef]

52. Acharya, U.R.; Fujita, H.; Sudarshan, V.K.; Oh, S.L.; Adam, M.; Koh, J.E.W.; Tan, J.H.; Ghista, D.N.; Martis, R.J.; Chua, C.K.; et al. Automated detection and localization of myocardial infarction using electrocardiogram: A comparative study of different leads. Knowl.-Based Syst. 2016, 99, 146-156. [CrossRef]

53. Han, C.; Shi, L. ML-ResNet: A novel network to detect and locate myocardial infarction using 12 leads ECG. Comput. Methods Programs Biomed. 2020, 185, 105138. [CrossRef]

54. Lih, O.S.; Jahmunah, V.; San, T.R.; Ciaccio, E.J.; Yamakawa, T.; Tanabe, M.; Kobayashi, M.; Faust, O.; Acharya, U.R. Comprehensive electrocardiographic diagnosis based on deep learning. Artif. Intell. Med. 2020, 103, 101789. [CrossRef]

55. Keller, T.; Zeller, T.; Ojeda, F.; Tzikas, S.; Lillpopp, L.; Sinning, C.; Wild, P.; Genth-Zotz, S.; Warnholtz, A.; Giannitsis, E. Serial changes in highly sensitive troponin I assay and early diagnosis of myocardial infarction. JAMA 2011, 306, 2684-2693. [CrossRef]

56. Collet, J.P.; Thiele, H.; Barbato, E.; Barthelemy, O.; Bauersachs, J.; Bhatt, D.L.; Dendale, P.; Dorobantu, M.; Edvardsen, T.; Folliguet, T.; et al. 2020 ESC Guidelines for the management of acute coronary syndromes in patients presenting without persistent ST-segment elevation. Eur. Heart J. 2021, 42, 1289-1367. [CrossRef]

57. Reichlin, T.; Schindler, C.; Drexler, B.; Twerenbold, R.; Reiter, M.; Zellweger, C.; Moehring, B.; Ziller, R.; Hoeller, R.; Rubini Gimenez, M.; et al. One-hour rule-out and rule-in of acute myocardial infarction using high-sensitivity cardiac troponin T. Arch. Intern. Med. 2012, 172, 1211-1218. [CrossRef]

58. Reichlin, T.; Twerenbold, R.; Wildi, K.; Gimenez, M.R.; Bergsma, N.; Haaf, P.; Druey, S.; Puelacher, C.; Moehring, B.; Freese, M.; et al. Prospective validation of a 1-hour algorithm to rule-out and rule-in acute myocardial infarction using a high-sensitivity cardiac troponin T assay. Can. Med. Assoc. J. 2015, 187, E243. [CrossRef]

59. Gimenez, M.R.; Twerenbold, R.; Jaeger, C.; Schindler, C.; Puelacher, C.; Wildi, K.; Reichlin, T.; Haaf, P.; Merk, S.; Honegger, U. One-hour rule-in and rule-out of acute myocardial infarction using high-sensitivity cardiac troponin I. Am. J. Med. 2015, 128, 861-870.e864. [CrossRef]

60. Druey, S.; Wildi, K.; Twerenbold, R.; Jaeger, C.; Reichlin, T.; Haaf, P.; Gimenez, M.R.; Puelacher, C.; Wagener, M.; Radosavac, M. Early rule-out and rule-in of myocardial infarction using sensitive cardiac Troponin I. Int. J. Cardiol. 2015, 195, 163-170. [CrossRef]

61. Neumann, J.T.; Sörensen, N.A.; Schwemer, T.; Ojeda, F.; Bourry, R.; Sciacca, V.; Schaefer, S.; Waldeyer, C.; Sinning, C.; Renné, T.; et al. Diagnosis of Myocardial Infarction Using a High-Sensitivity Troponin I 1-Hour Algorithm. JAMA Cardiol. 2016, 1, $397-404$. [CrossRef]

62. Twerenbold, R.; Badertscher, P.; Boeddinghaus, J.; Nestelberger, T.; Wildi, K.; Puelacher, C.; Sabti, Z.; Gimenez, M.R.; Tschirky, S.; Lavallaz, J.d.F.d.; et al. 0/1-Hour Triage Algorithm for Myocardial Infarction in Patients with Renal Dysfunction. Circulation 2018, 137, 436-451. [CrossRef]

63. Boeddinghaus, J.; Nestelberger, T.; Twerenbold, R.; Neumann, J.T.; Lindahl, B.; Giannitsis, E.; Sörensen, N.A.; Badertscher, P.; Jann, J.E.; Wussler, D.; et al. Impact of age on the performance of the ESC 0/1h-algorithms for early diagnosis of myocardial infarction. Eur. Heart J. 2018, 39, 3780-3794. [CrossRef]

64. McCarthy, C.P.; Neumann, J.T.; Michelhaugh, S.A.; Ibrahim, N.E.; Gaggin, H.K.; Sorensen, N.A.; Schaefer, S.; Zeller, T.; Magaret, C.A.; Barnes, G.; et al. Derivation and External Validation of a High-Sensitivity Cardiac Troponin-Based Proteomic Model to Predict the Presence of Obstructive Coronary Artery Disease. J. Am. Heart Assoc. 2020, 9, e017221. [CrossRef]

65. Liu, C.Y.; Tang, C.X.; Zhang, X.L.; Chen, S.; Xie, Y.; Zhang, X.Y.; Qiao, H.Y.; Zhou, C.S.; Xu, P.P.; Lu, M.J.; et al. Deep learning powered coronary $\mathrm{CT}$ angiography for detecting obstructive coronary artery disease: The effect of reader experience, calcification and image quality. Eur. J. Radiol. 2021, 142, 109835. [CrossRef]

66. Lee, J.-G.; Kim, H.; Kang, H.; Koo, H.J.; Kang, J.-W.; Kim, Y.-H.; Yang, D.H. Fully Automatic Coronary Calcium Score Software Empowered by Artificial Intelligence Technology: Validation Study Using Three CT Cohorts. Korean J. Radiol. 2021, 22, 1764-1776. [CrossRef] 
67. van Velzen, S.G.M.; Lessmann, N.; Velthuis, B.K.; Bank, I.E.M.; van den Bongard, D.; Leiner, T.; de Jong, P.A.; Veldhuis, W.B.; Correa, A.; Terry, J.G.; et al. Deep Learning for Automatic Calcium Scoring in CT: Validation Using Multiple Cardiac CT and Chest CT Protocols. Radiology 2020, 295, 66-79. [CrossRef]

68. Baskaran, L.; Maliakal, G.; Al'Aref, S.J.; Singh, G.; Xu, Z.; Michalak, K.; Dolan, K.; Gianni, U.; van Rosendael, A.; van den Hoogen, I.; et al. Identification and Quantification of Cardiovascular Structures From CCTA: An End-to-End, Rapid, Pixel-Wise, Deep-Learning Method. JACC Cardiovasc. Imaging 2020, 13, 1163-1171. [CrossRef]

69. Wang, W.; Wang, H.; Chen, Q.; Zhou, Z.; Wang, R.; Wang, H.; Zhang, N.; Chen, Y.; Sun, Z.; Xu, L. Coronary artery calcium score quantification using a deep-learning algorithm. Clin. Radiol. 2020, 75, 237.e11-237.e16. [CrossRef]

70. von Knebel Doeberitz, P.L.; De Cecco, C.N.; Schoepf, U.J.; Duguay, T.M.; Albrecht, M.H.; van Assen, M.; Bauer, M.J.; Savage, R.H.; Pannell, J.T.; De Santis, D.; et al. Coronary CT angiography-derived plaque quantification with artificial intelligence CT fractional flow reserve for the identification of lesion-specific ischemia. Eur. Radiol. 2019, 29, 2378-2387. [CrossRef]

71. Koo, H.J.; Lee, J.G.; Ko, J.Y.; Lee, G.; Kang, J.W.; Kim, Y.H.; Yang, D.H. Automated Segmentation of Left Ventricular Myocardium on Cardiac Computed Tomography Using Deep Learning. Korean J. Radiol. 2020, 21, 660-669. [CrossRef]

72. Morris, E.D.; Ghanem, A.I.; Dong, M.; Pantelic, M.V.; Walker, E.M.; Glide-Hurst, C.K. Cardiac substructure segmentation with deep learning for improved cardiac sparing. Med. Phys. 2020, 47, 576-586. [CrossRef]

73. Muscogiuri, G.; Chiesa, M.; Trotta, M.; Gatti, M.; Palmisano, V.; Dell'Aversana, S.; Baessato, F.; Cavaliere, A.; Cicala, G.; Loffreno, A.; et al. Performance of a deep learning algorithm for the evaluation of CAD-RADS classification with CCTA. Atherosclerosis 2020, 294, 25-32. [CrossRef]

74. Fihn, S.D.; Gardin, J.M.; Abrams, J.; Berra, K.; Blankenship, J.C.; Dallas, A.P.; Douglas, P.S.; Foody, J.M.; Gerber, T.C.; Hinderliter, A.L.; et al. 2012 ACCF/AHA/ACP/AATS/PCNA/SCAI/STS Guideline for the Diagnosis and Management of Patients With Stable Ischemic Heart Disease. Circulation 2012, 126, e354-e471. [CrossRef]

75. Biagini, E.; Shaw, L.J.; Poldermans, D.; Schinkel, A.F.; Rizzello, V.; Elhendy, A.; Rapezzi, C.; Bax, J.J. Accuracy of non-invasive techniques for diagnosis of coronary artery disease and prediction of cardiac events in patients with left bundle branch block: A meta-analysis. Eur. J. Nucl. Med. Mol. Imaging 2006, 33, 1442-1451. [CrossRef]

76. Mahajan, N.; Polavaram, L.; Vankayala, H.; Ference, B.; Wang, Y.; Ager, J.; Kovach, J.; Afonso, L. Diagnostic accuracy of myocardial perfusion imaging and stress echocardiography for the diagnosis of left main and triple vessel coronary artery disease: A comparative meta-analysis. Heart 2010, 96, 956-966. [CrossRef]

77. Jaarsma, C.; Leiner, T.; Bekkers Sebastiaan, C.; Crijns Harry, J.; Wildberger Joachim, E.; Nagel, E.; Nelemans Patricia, J.; Schalla, S. Diagnostic Performance of Noninvasive Myocardial Perfusion Imaging Using Single-Photon Emission Computed Tomography, Cardiac Magnetic Resonance, and Positron Emission Tomography Imaging for the Detection of Obstructive Coronary Artery Disease. J. Am. Coll. Cardiol. 2012, 59, 1719-1728. [CrossRef]

78. Takx, R.A.P.; Blomberg, B.A.; Aidi, H.E.; Habets, J.; de Jong, P.A.; Nagel, E.; Hoffmann, U.; Leiner, T. Diagnostic Accuracy of Stress Myocardial Perfusion Imaging Compared to Invasive Coronary Angiography With Fractional Flow Reserve Meta-Analysis. Circ. Cardiovasc. Imaging 2015, 8, e002666. [CrossRef]

79. Fleischmann, K.E.; Hunink, M.G.; Kuntz, K.M.; Douglas, P.S. Exercise echocardiography or exercise SPECT imaging? A meta-analysis of diagnostic test performance. JAMA 1998, 280, 913-920. [CrossRef]

80. Holder, L.; Lewis, S.; Abrames, E.; Wolin, E.A. Review of SPECT myocardial perfusion imaging. J. Am. Osteopath. Coll. Radiol. 2016, 5, 5-13.

81. Czaja, M.; Wygoda, Z.; Duszańska, A.; Szczerba, D.; Głowacki, J.; Gassior, M.; Wasilewski, J.P. Interpreting myocardial perfusion scintigraphy using single-photon emission computed tomography. Part 1. Kardiochir. Torakochirurgia Pol. 2017, 14, 192-199. [CrossRef]

82. Slomka, P.; Xu, Y.; Berman, D.; Germano, G. Quantitative analysis of perfusion studies: Strengths and pitfalls. J. Nucl. Cardiol. Off. Publ. Am. Soc. Nucl. Cardiol. 2012, 19, 338-346. [CrossRef]

83. Hachamovitch, R.; Hayes, S.W.; Friedman, J.D.; Cohen, I.; Berman, D.S. A prognostic score for prediction of cardiac mortality risk after adenosine stress myocardial perfusion scintigraphy. J. Am. Coll. Cardiol. 2005, 45, 722-729. [CrossRef]

84. Arsanjani, R.; Xu, Y.; Hayes, S.W.; Fish, M.; Lemley, M., Jr.; Gerlach, J.; Dorbala, S.; Berman, D.S.; Germano, G.; Slomka, P. Comparison of fully automated computer analysis and visual scoring for detection of coronary artery disease from myocardial perfusion SPECT in a large population. J. Nucl. Med. 2013, 54, 221-228. [CrossRef]

85. Hu, L.H.; Betancur, J.; Sharir, T.; Einstein, A.J.; Bokhari, S.; Fish, M.B.; Ruddy, T.D.; Kaufmann, P.A.; Sinusas, A.J.; Miller, E.J.; et al. Machine learning predicts per-vessel early coronary revascularization after fast myocardial perfusion SPECT: Results from multicentre REFINE SPECT registry. Eur. Heart J. Cardiovasc. Imaging 2020, 21, 549-559. [CrossRef]

86. Arsanjani, R.; Dey, D.; Khachatryan, T.; Shalev, A.; Hayes, S.W.; Fish, M.; Nakanishi, R.; Germano, G.; Berman, D.S.; Slomka, P. Prediction of revascularization after myocardial perfusion SPECT by machine learning in a large population. J. Nucl. Cardiol. 2015, 22, 877-884. [CrossRef]

87. Koo, B.K.; Erglis, A.; Doh, J.H.; Daniels, D.V.; Jegere, S.; Kim, H.S.; Dunning, A.; DeFrance, T.; Lansky, A.; Leipsic, J.; et al. Diagnosis of ischemia-causing coronary stenoses by noninvasive fractional flow reserve computed from coronary computed tomographic angiograms. Results from the prospective multicenter DISCOVER-FLOW (Diagnosis of Ischemia-Causing Stenoses Obtained Via Noninvasive Fractional Flow Reserve) study. J. Am. Coll. Cardiol. 2011, 58, 1989-1997. [CrossRef] 
88. Min, J.K.; Berman, D.S.; Budoff, M.J.; Jaffer, F.A.; Leipsic, J.; Leon, M.B.; Mancini, G.B.; Mauri, L.; Schwartz, R.S.; Shaw, L.J. Rationale and design of the DeFACTO (Determination of Fractional Flow Reserve by Anatomic Computed Tomographic AngiOgraphy) study. J. Cardiovasc. Comput. Tomogr. 2011, 5, 301-309. [CrossRef]

89. Nørgaard, B.L.; Leipsic, J.; Gaur, S.; Seneviratne, S.; Ko, B.S.; Ito, H.; Jensen, J.M.; Mauri, L.; Bruyne, B.D.; Bezerra, H.; et al. Diagnostic Performance of Noninvasive Fractional Flow Reserve Derived From Coronary Computed Tomography Angiography in Suspected Coronary Artery Disease. J. Am. Coll. Cardiol. 2014, 63, 1145-1155. [CrossRef]

90. Rabbat, M.G.; Berman, D.S.; Kern, M.; Raff, G.; Chinnaiyan, K.; Koweek, L.; Shaw, L.J.; Blanke, P.; Scherer, M.; Jensen, J.M.; et al. Interpreting results of coronary computed tomography angiography-derived fractional flow reserve in clinical practice. J. Cardiovasc. Comput. Tomogr. 2017, 11, 383-388. [CrossRef]

91. Rabbat, M.; Leipsic, J.; Bax, J.; Kauh, B.; Verma, R.; Doukas, D.; Allen, S.; Pontone, G.; Wilber, D.; Mathew, V.; et al. Fractional Flow Reserve Derived from Coronary Computed Tomography Angiography Safely Defers Invasive Coronary Angiography in Patients with Stable Coronary Artery Disease. J. Clin. Med. 2020, 9, 604. [CrossRef]

92. Yeri, A.; Shah, R.V. Comparison of Computational Fluid Dynamics and Machine Learning-Based Fractional Flow Reserve in Coronary Artery Disease. Circ. Cardiovasc. Imaging 2018, 11, e007950. [CrossRef]

93. Itu, L.; Rapaka, S.; Passerini, T.; Georgescu, B.; Schwemmer, C.; Schoebinger, M.; Flohr, T.; Sharma, P.; Comaniciu, D. A machinelearning approach for computation of fractional flow reserve from coronary computed tomography. J. Appl. Physiol. 2016, 121, 42-52. [CrossRef]

94. Han, D.; Lee, J.H.; Rizvi, A.; Gransar, H.; Baskaran, L.; Schulman-Marcus, J.; Hartaigh, B.ó.; Lin, F.Y.; Min, J.K. Incremental role of resting myocardial computed tomography perfusion for predicting physiologically significant coronary artery disease: A machine learning approach. J. Nucl. Cardiol. 2018, 25, 223-233. [CrossRef]

95. Zreik, M.; Lessmann, N.; van Hamersvelt, R.W.; Wolterink, J.M.; Voskuil, M.; Viergever, M.A.; Leiner, T.; Isgum, I. Deep learning analysis of the myocardium in coronary $\mathrm{CT}$ angiography for identification of patients with functionally significant coronary artery stenosis. Med. Image Anal. 2018, 44, 72-85. [CrossRef]

96. Zreik, M.; van Hamersvelt, R.W.; Khalili, N.; Wolterink, J.M.; Voskuil, M.; Viergever, M.A.; Leiner, T.; Isgum, I. Deep Learning Analysis of Coronary Arteries in Cardiac CT Angiography for Detection of Patients Requiring Invasive Coronary Angiography. IEEE Trans. Med. Imaging 2020, 39, 1545-1557. [CrossRef]

97. Coenen, A.; Kim, Y.H.; Kruk, M.; Tesche, C.; De Geer, J.; Kurata, A.; Lubbers, M.L.; Daemen, J.; Itu, L.; Rapaka, S.; et al. Diagnostic Accuracy of a Machine-Learning Approach to Coronary Computed Tomographic Angiography-Based Fractional Flow Reserve: Result From the MACHINE Consortium. Circ. Cardiovasc. Imaging 2018, 11, e007217. [CrossRef]

98. Di Jiang, M.; Zhang, X.L.; Liu, H.; Tang, C.X.; Li, J.H.; Wang, Y.N.; Xu, P.P.; Zhou, C.S.; Zhou, F.; Lu, M.J.; et al. The effect of coronary calcification on diagnostic performance of machine learning-based CT-FFR: A Chinese multicenter study. Eur. Radiol. 2021, 31, 1482-1493. [CrossRef]

99. Koo, H.J.; Kang, J.W.; Kang, S.J.; Kweon, J.; Lee, J.G.; Ahn, J.M.; Park, D.W.; Lee, S.W.; Lee, C.W.; Park, S.W.; et al. Impact of coronary calcium score and lesion characteristics on the diagnostic performance of machine-learning-based computed tomography-derived fractional flow reserve. Eur. Heart J. Cardiovasc. Imaging 2021, 22, 998-1006. [CrossRef]

100. Kumamaru, K.K.; Fujimoto, S.; Otsuka, Y.; Kawasaki, T.; Kawaguchi, Y.; Kato, E.; Takamura, K.; Aoshima, C.; Kamo, Y.; Kogure, Y.; et al. Diagnostic accuracy of 3D deep-learning-based fully automated estimation of patient-level minimum fractional flow reserve from coronary computed tomography angiography. Eur. Heart J. Cardiovasc. Imaging 2020, 21, 437-445. [CrossRef]

101. Kurata, A.; Fukuyama, N.; Hirai, K.; Kawaguchi, N.; Tanabe, Y.; Okayama, H.; Shigemi, S.; Watanabe, K.; Uetani, T.; Ikeda, S.; et al. On-Site Computed Tomography-Derived Fractional Flow Reserve Using a Machine-Learning Algorithm-Clinical Effectiveness in a Retrospective Multicenter Cohort. Circ. J. 2019, 83, 1563-1571. [CrossRef]

102. Rother, J.; Moshage, M.; Dey, D.; Schwemmer, C.; Trobs, M.; Blachutzik, F.; Achenbach, S.; Schlundt, C.; Marwan, M. Comparison of invasively measured FFR with FFR derived from coronary CT angiography for detection of lesion-specific ischemia: Results from a PC-based prototype algorithm. J. Cardiovasc. Comput. Tomogr. 2018, 12, 101-107. [CrossRef]

103. Tang, C.X.; Wang, Y.N.; Zhou, F.; Schoepf, U.J.; Assen, M.V.; Stroud, R.E.; Li, J.H.; Zhang, X.L.; Lu, M.J.; Zhou, C.S.; et al. Diagnostic performance of fractional flow reserve derived from coronary CT angiography for detection of lesion-specific ischemia: A multi-center study and meta-analysis. Eur. J. Radiol. 2019, 116, 90-97. [CrossRef]

104. Tesche, C.; Otani, K.; De Cecco, C.N.; Coenen, A.; De Geer, J.; Kruk, M.; Kim, Y.H.; Albrecht, M.H.; Baumann, S.; Renker, M.; et al. Influence of Coronary Calcium on Diagnostic Performance of Machine Learning CT-FFR: Results From MACHINE Registry. JACC Cardiovasc. Imaging 2020, 13, 760-770. [CrossRef]

105. Wang, Z.Q.; Zhou, Y.J.; Zhao, Y.X.; Shi, D.M.; Liu, Y.Y.; Liu, W.; Liu, X.L.; Li, Y.P. Diagnostic accuracy of a deep learning approach to calculate FFR from coronary CT angiography. J. Geriatr. Cardiol. 2019, 16, 42-48. [CrossRef]

106. Wardziak, L.; Kruk, M.; Pleban, W.; Demkow, M.; Ruzyllo, W.; Dzielinska, Z.; Kepka, C. Coronary CTA enhanced with CTA based FFR analysis provides higher diagnostic value than invasive coronary angiography in patients with intermediate coronary stenosis. J. Cardiovasc. Comput. Tomogr. 2019, 13, 62-67. [CrossRef]

107. Tesche, C.; De Cecco, C.N.; Baumann, S.; Renker, M.; McLaurin, T.W.; Duguay, T.M.; Bayer, R.R., 2nd; Steinberg, D.H.; Grant, K.L.; Canstein, C.; et al. Coronary CT Angiography-derived Fractional Flow Reserve: Machine Learning Algorithm versus Computational Fluid Dynamics Modeling. Radiology 2018, 288, 64-72. [CrossRef] 
108. Arbab-Zadeh, A.; Miller, J.M.; Rochitte, C.E.; Dewey, M.; Niinuma, H.; Gottlieb, I.; Paul, N.; Clouse, M.E.; Shapiro, E.P.; Hoe, J.; et al. Diagnostic accuracy of computed tomography coronary angiography according to pre-test probability of coronary artery disease and severity of coronary arterial calcification. The CORE-64 (Coronary Artery Evaluation Using 64-Row Multidetector Computed Tomography Angiography) International Multicenter Study. J. Am. Coll. Cardiol. 2012, 59, $379-387$. [CrossRef]

109. Chen, C.-C.; Chen, C.-C.; Hsieh, I.C.; Liu, Y.-C.; Liu, C.-Y.; Chan, T.; Wen, M.-S.; Wan, Y.-L. The effect of calcium score on the diagnostic accuracy of coronary computed tomography angiography. Int. J. Cardiovasc. Imaging 2011, 27, 37-42. [CrossRef]

110. Vavere, A.L.; Arbab-Zadeh, A.; Rochitte, C.E.; Dewey, M.; Niinuma, H.; Gottlieb, I.; Clouse, M.E.; Bush, D.E.; Hoe, J.W.M.; de Roos, A.; et al. Coronary artery stenoses: Accuracy of 64-detector row CT angiography in segments with mild, moderate, or severe calcification-a subanalysis of the CORE-64 trial. Radiology 2011, 261, 100-108. [CrossRef]

111. Arjmand Shabestari, A. Coronary artery calcium score: A review. Iran Red. Crescent. Med. J. 2013, 15, e16616. [CrossRef]

112. Agatston, A.S.; Janowitz, W.R.; Hildner, F.J.; Zusmer, N.R.; Viamonte, M., Jr.; Detrano, R. Quantification of coronary artery calcium using ultrafast computed tomography. J. Am. Coll. Cardiol. 1990, 15, 827-832. [CrossRef]

113. Yu, M.; Li, Y.; Li, W.; Lu, Z.; Wei, M.; Zhang, J. Calcification remodeling index assessed by cardiac CT predicts severe coronary stenosis in lesions with moderate to severe calcification. J. Cardiovasc. Comput. Tomogr. 2018, 12, 42-49. [CrossRef]

114. Sekimoto, T.; Akutsu, Y.; Hamazaki, Y.; Sakai, K.; Kosaki, R.; Yokota, H.; Tsujita, H.; Tsukamoto, S.; Kaneko, K.; Sakurai, M.; et al. Regional calcified plaque score evaluated by multidetector computed tomography for predicting the addition of rotational atherectomy during percutaneous coronary intervention. J. Cardiovasc. Comput. Tomogr. 2016, 10, 221-228. [CrossRef]

115. Qiao, H.Y.; Tang, C.X.; Schoepf, U.J.; Tesche, C.; Bayer, R.R., 2nd; Giovagnoli, D.A.; Todd Hudson, H., Jr.; Zhou, C.S.; Yan, J.; Lu, M.J.; et al. Impact of machine learning-based coronary computed tomography angiography fractional flow reserve on treatment decisions and clinical outcomes in patients with suspected coronary artery disease. Eur. Radiol. 2020, 30, 5841-5851. [CrossRef]

116. Liu, X.; Mo, X.; Zhang, H.; Yang, G.; Shi, C.; Hau, W.K. A 2-year investigation of the impact of the computed tomography-derived fractional flow reserve calculated using a deep learning algorithm on routine decision-making for coronary artery disease management. Eur. Radiol. 2021, 31, 7039-7046. [CrossRef]

117. Martin, S.S.; Mastrodicasa, D.; van Assen, M.; De Cecco, C.N.; Bayer, R.R.; Tesche, C.; Varga-Szemes, A.; Fischer, A.M.; Jacobs, B.E.; Sahbaee, P.; et al. Value of Machine Learning-based Coronary CT Fractional Flow Reserve Applied to Triple-Rule-Out CT Angiography in Acute Chest Pain. Radiol. Cardiothorac. Imaging 2020, 2, e190137. [CrossRef]

118. Nous, F.M.A.; Budde, R.P.J.; Lubbers, M.M.; Yamasaki, Y.; Kardys, I.; Bruning, T.A.; Akkerhuis, J.M.; Kofflard, M.J.M.; Kietselaer, B.; Galema, T.W.; et al. Impact of machine-learning CT-derived fractional flow reserve for the diagnosis and management of coronary artery disease in the randomized CRESCENT trials. Eur. Radiol. 2020, 30, 3692-3701. [CrossRef]

119. Cook, C.M.; Petraco, R.; Shun-Shin, M.J.; Ahmad, Y.; Nijjer, S.; Al-Lamee, R.; Kikuta, Y.; Shiono, Y.; Mayet, J.; Francis, D.P.; et al. Diagnostic Accuracy of Computed Tomography-Derived Fractional Flow Reserve: A Systematic Review. JAMA Cardiol. 2017, 2, 803-810. [CrossRef]

120. Gaur, S.; Ovrehus, K.A.; Dey, D.; Leipsic, J.; Botker, H.E.; Jensen, J.M.; Narula, J.; Ahmadi, A.; Achenbach, S.; Ko, B.S.; et al. Coronary plaque quantification and fractional flow reserve by coronary computed tomography angiography identify ischaemiacausing lesions. Eur. Heart J. 2016, 37, 1220-1227. [CrossRef]

121. Kawasaki, T.; Kidoh, M.; Kido, T.; Sueta, D.; Fujimoto, S.; Kumamaru, K.K.; Uetani, T.; Tanabe, Y.; Ueda, T.; Sakabe, D.; et al. Evaluation of Significant Coronary Artery Disease Based on CT Fractional Flow Reserve and Plaque Characteristics Using Random Forest Analysis in Machine Learning. Acad. Radiol. 2020, 27, 1700-1708. [CrossRef]

122. Vasquez, A.; Mistry, N.; Singh, J. Impact of Intravascular Ultrasound in Clinical Practice. Interv. Cardiol. 2014, 9, 156-163. [CrossRef]

123. Metz, J.A.; Yock, P.G.; Fitzgerald, P.J. Intravascular ultrasound: Basic interpretation. Cardiol. Clin. 1997, 15, 1-15. [CrossRef]

124. Ma, T.; Yu, M.; Li, J.; Munding, C.E.; Chen, Z.; Fei, C.; Shung, K.K.; Zhou, Q. Multi-frequency intravascular ultrasound (IVUS) imaging. IEEE Trans. Ultrason. Ferroelectr. Freq. Control 2015, 62, 97-107. [CrossRef]

125. Pu, J.; Mintz, G.S.; Biro, S.; Lee, J.-B.; Sum, S.T.; Madden, S.P.; Burke, A.P.; Zhang, P.; He, B.; Goldstein, J.A.; et al. Insights Into Echo-Attenuated Plaques, Echolucent Plaques, and Plaques With Spotty Calcification: Novel Findings From Comparisons Among Intravascular Ultrasound, Near-Infrared Spectroscopy, and Pathological Histology in 2294 Human Coronary Artery Segments. J. Am. Coll. Cardiol. 2014, 63, 2220-2233. [CrossRef]

126. Mintz, G.S.; Pichard, A.D.; Popma, J.J.; Kent, K.M.; Satler, L.F.; Bucher, T.A.; Leon, M.B. Determinants and Correlates of Target Lesion Calcium in Coronary Artery Disease: A Clinical, Angiographic and Intravascular Ultrasound Study. J. Am. Coll. Cardiol. 1997, 29, 268-274. [CrossRef]

127. Kobayashi, Y.; Okura, H.; Kume, T.; Yamada, R.; Kobayashi, Y.; Fukuhara, K.; Koyama, T.; Nezuo, S.; Neishi, Y.; Hayashida, A.; et al. Impact of target lesion coronary calcification on stent expansion. Circ. J. 2014, 78, 2209-2214. [CrossRef]

128. Nair, A.; Kuban, B.D.; Tuzcu, E.M.; Schoenhagen, P.; Nissen, S.E.; Vince, D.G. Coronary Plaque Classification With Intravascular Ultrasound Radiofrequency Data Analysis. Circulation 2002, 106, 2200-2206. [CrossRef]

129. Sonoda, S.; Hibi, K.; Okura, H.; Fujii, K.; Honda, Y.; Kobayashi, Y. Current clinical use of intravascular ultrasound imaging to guide percutaneous coronary interventions. Cardiovasc. Interv. 2020, 35, 30-36. [CrossRef] 
130. Maehara, A.; Matsumura, M.; Ali, Z.A.; Mintz, G.S.; Stone, G.W. IVUS-Guided Versus OCT-Guided Coronary Stent Implantation: A Critical Appraisal. JACC Cardiovasc. Imaging 2017, 10, 1487-1503. [CrossRef]

131. Malik, A.H.; Yandrapalli, S.; Aronow, W.S.; Panza, J.A.; Cooper, H.A. Intravascular ultrasound-guided stent implantation reduces cardiovascular mortality-Updated meta-analysis of randomized controlled trials. Int. J. Cardiol. 2020, 299, 100-105. [CrossRef]

132. Chieffo, A.; Latib, A.; Caussin, C.; Presbitero, P.; Galli, S.; Menozzi, A.; Varbella, F.; Mauri, F.; Valgimigli, M.; Arampatzis, C.; et al. A prospective, randomized trial of intravascular-ultrasound guided compared to angiography guided stent implantation in complex coronary lesions: The AVIO trial. Am. Heart J. 2013, 165, 65-72. [CrossRef]

133. Sinclair, H.; Bourantas, C.; Bagnall, A.; Mintz, G.S.; Kunadian, V. OCT for the identification of vulnerable plaque in acute coronary syndrome. JACC Cardiovasc. Imaging 2015, 8, 198-209. [CrossRef]

134. Cheng, J.M.; Garcia-Garcia, H.M.; de Boer, S.P.; Kardys, I.; Heo, J.H.; Akkerhuis, K.M.; Oemrawsingh, R.M.; van Domburg, R.T.; Ligthart, J.; Witberg, K.T.; et al. In vivo detection of high-risk coronary plaques by radiofrequency intravascular ultrasound and cardiovascular outcome: Results of the ATHEROREMO-IVUS study. Eur. Heart J. 2014, 35, 639-647. [CrossRef]

135. Räber, L.; Ueki, Y. Outcomes of Intravascular Ultrasound-Guided Percutaneous Coronary Intervention in the United States. JACC Cardiovasc. Interv. 2020, 13, 1891-1893. [CrossRef]

136. Ali, Z.A.; Karimi Galougahi, K.; Maehara, A.; Shlofmitz, R.A.; Ben-Yehuda, O.; Mintz, G.S.; Stone, G.W. Intracoronary Optical Coherence Tomography 2018: Current Status and Future Directions. JACC Cardiovasc. Interv. 2017, 10, 2473-2487. [CrossRef]

137. Bae, Y.; Kang, S.J.; Kim, G.; Lee, J.G.; Min, H.S.; Cho, H.; Kang, D.Y.; Lee, P.H.; Ahn, J.M.; Park, D.W.; et al. Prediction of coronary thin-cap fibroatheroma by intravascular ultrasound-based machine learning. Atherosclerosis 2019, 288, 168-174. [CrossRef]

138. Min, H.S.; Yoo, J.H.; Kang, S.J.; Lee, J.G.; Cho, H.; Lee, P.H.; Ahn, J.M.; Park, D.W.; Lee, S.W.; Kim, Y.H.; et al. Detection of optical coherence tomography-defined thin-cap fibroatheroma in the coronary artery using deep learning. EuroIntervention 2020, 16, 404-412. [CrossRef]

139. Cho, H.; Kang, S.J.; Min, H.S.; Lee, J.G.; Kim, W.J.; Kang, S.H.; Kang, D.Y.; Lee, P.H.; Ahn, J.M.; Park, D.W.; et al. Intravascular ultrasound-based deep learning for plaque characterization in coronary artery disease. Atherosclerosis 2021, 324, 69-75. [CrossRef]

140. Hong, M.K.; Mintz, G.S.; Lee, C.W.; Park, D.W.; Choi, B.R.; Park, K.H.; Kim, Y.H.; Cheong, S.S.; Song, J.K.; Kim, J.J.; et al. Intravascular ultrasound predictors of angiographic restenosis after sirolimus-eluting stent implantation. Eur. Heart J. 2006, 27, 1305-1310. [CrossRef]

141. Song, H.G.; Kang, S.J.; Ahn, J.M.; Kim, W.J.; Lee, J.Y.; Park, D.W.; Lee, S.W.; Kim, Y.H.; Lee, C.W.; Park, S.W.; et al. Intravascular ultrasound assessment of optimal stent area to prevent in-stent restenosis after zotarolimus-, everolimus-, and sirolimus-eluting stent implantation. Catheter. Cardiovasc. Interv. 2014, 83, 873-878. [CrossRef] [PubMed]

142. Fujii, K.; Carlier, S.G.; Mintz, G.S.; Yang, Y.M.; Moussa, I.; Weisz, G.; Dangas, G.; Mehran, R.; Lansky, A.J.; Kreps, E.M.; et al. Stent underexpansion and residual reference segment stenosis are related to stent thrombosis after sirolimus-eluting stent implantation: An intravascular ultrasound study. J. Am. Coll. Cardiol. 2005, 45, 995-998. [CrossRef] [PubMed]

143. Doi, H.; Maehara, A.; Mintz, G.S.; Yu, A.; Wang, H.; Mandinov, L.; Popma, J.J.; Ellis, S.G.; Grube, E.; Dawkins, K.D.; et al. Impact of post-intervention minimal stent area on 9-month follow-up patency of paclitaxel-eluting stents: An integrated intravascular ultrasound analysis from the TAXUS IV, V, and VI and TAXUS ATLAS Workhorse, Long Lesion, and Direct Stent Trials. JACC Cardiovasc. Interv. 2009, 2, 1269-1275. [CrossRef] [PubMed]

144. Min, H.S.; Ryu, D.; Kang, S.J.; Lee, J.G.; Yoo, J.H.; Cho, H.; Kang, D.Y.; Lee, P.H.; Ahn, J.M.; Park, D.W.; et al. Prediction of Coronary Stent Underexpansion by Pre-Procedural Intravascular Ultrasound-Based Deep Learning. JACC Cardiovasc. Interv. 2021, 14, 1021-1029. [CrossRef]

145. Nishi, T.; Yamashita, R.; Imura, S.; Tateishi, K.; Kitahara, H.; Kobayashi, Y.; Yock, P.G.; Fitzgerald, P.J.; Honda, Y. Deep learningbased intravascular ultrasound segmentation for the assessment of coronary artery disease. Int. J. Cardiol. 2021, 333, 55-59. [CrossRef] [PubMed]

146. Brown, A.J.; Teng, Z.; Calvert, P.A.; Rajani, N.K.; Hennessy, O.; Nerlekar, N.; Obaid, D.R.; Costopoulos, C.; Huang, Y.; Hoole, S.P.; et al. Plaque Structural Stress Estimations Improve Prediction of Future Major Adverse Cardiovascular Events After Intracoronary Imaging. Circ. Cardiovasc. Imaging 2016, 9, e004172. [CrossRef]

147. Xie, Z.; Dong, N.; Sun, R.; Liu, X.; Gu, X.; Sun, Y.; Du, H.; Dai, J.; Liu, Y.; Hou, J.; et al. Relation between baseline plaque features and subsequent coronary artery remodeling determined by optical coherence tomography and intravascular ultrasound. Oncotarget 2017, 8, 4234-4244. [CrossRef]

148. Stone, P.H.; Saito, S.; Takahashi, S.; Makita, Y.; Nakamura, S.; Kawasaki, T.; Takahashi, A.; Katsuki, T.; Nakamura, S.; Namiki, A.; et al. Prediction of progression of coronary artery disease and clinical outcomes using vascular profiling of endothelial shear stress and arterial plaque characteristics: The PREDICTION Study. Circulation 2012, 126, 172-181. [CrossRef]

149. Calvert, P.A.; Obaid, D.R.; O'Sullivan, M.; Shapiro, L.M.; McNab, D.; Densem, C.G.; Schofield, P.M.; Braganza, D.; Clarke, S.C.; Ray, K.K.; et al. Association between IVUS findings and adverse outcomes in patients with coronary artery disease: The VIVA (VH-IVUS in Vulnerable Atherosclerosis) Study. JACC Cardiovasc. Imaging 2011, 4, 894-901. [CrossRef]

150. Zhang, L.; Wahle, A.; Chen, Z.; Lopez, J.J.; Kovarnik, T.; Sonka, M. Predicting Locations of High-Risk Plaques in Coronary Arteries in Patients Receiving Statin Therapy. IEEE Trans. Med. Imaging 2018, 37, 151-161. [CrossRef]

151. Farooq, V.; Brugaletta, S.; Serruys, P.W. The SYNTAX score and SYNTAX-based clinical risk scores. Semin Thorac Cardiovasc Surg 2011, 23, 99-105. [CrossRef] [PubMed] 
152. Singh, M.; Rihal, C.S.; Lennon, R.J.; Spertus, J.; Rumsfeld, J.S.; Holmes, D.R., Jr. Bedside estimation of risk from percutaneous coronary intervention: The new Mayo Clinic risk scores. Mayo Clin. Proc. 2007, 82, 701-708. [CrossRef]

153. Chowdhary, S.; Ivanov, J.; Mackie, K.; Seidelin, P.H.; Dzavík, V. The Toronto score for in-hospital mortality after percutaneous coronary interventions. Am. Heart J. 2009, 157, 156-163. [CrossRef] [PubMed]

154. Hannan, E.L.; Farrell, L.S.; Walford, G.; Jacobs, A.K.; Berger, P.B.; Holmes, D.R., Jr.; Stamato, N.J.; Sharma, S.; King, S.B., 3rd. The New York State risk score for predicting in-hospital/30-day mortality following percutaneous coronary intervention. JACC Cardiovasc. Interv. 2013, 6, 614-622. [CrossRef] [PubMed]

155. MacKenzie, T.A.; Malenka, D.J.; Olmstead, E.M.; Piper, W.D.; Langner, C.; Ross, C.S.; O'Connor, G.T. Prediction of survival after coronary revascularization: Modeling short-term, mid-term, and long-term survival. Ann. Thorac. Surg. 2009, 87, 463-472. [CrossRef] [PubMed]

156. O'Connor, G.T.; Malenka, D.J.; Quinton, H.; Robb, J.F.; Kellett, M.A., Jr.; Shubrooks, S.; Bradley, W.A.; Hearne, M.J.; Watkins, M.W.; Wennberg, D.E.; et al. Multivariate prediction of in-hospital mortality after percutaneous coronary interventions in 1994-1996. Northern New England Cardiovascular Disease Study Group. J. Am. Coll. Cardiol. 1999, 34, 681-691. [CrossRef]

157. Rihal, C.S.; Grill, D.E.; Bell, M.R.; Berger, P.B.; Garratt, K.N.; Holmes, D.R., Jr. Prediction of death after percutaneous coronary interventional procedures. Am. Heart J. 2000, 139, 1032-1038. [CrossRef]

158. Wu, C.; Hannan, E.L.; Walford, G.; Ambrose, J.A.; Holmes, D.R., Jr.; King, S.B., 3rd; Clark, L.T.; Katz, S.; Sharma, S.; Jones, R.H. A risk score to predict in-hospital mortality for percutaneous coronary interventions. J. Am. Coll. Cardiol. 2006, 47, 654-660. [CrossRef]

159. Fanaroff, A.C.; Zakroysky, P.; Dai, D.; Wojdyla, D.; Sherwood, M.W.; Roe, M.T.; Wang, T.Y.; Peterson, E.D.; Gurm, H.S.; Cohen, M.G.; et al. Outcomes of PCI in Relation to Procedural Characteristics and Operator Volumes in the United States. J. Am. Coll. Cardiol. 2017, 69, 2913-2924. [CrossRef]

160. Iverson, A.; Stanberry, L.I.; Tajti, P.; Garberich, R.; Antos, A.; Burke, M.N.; Chavez, I.; Gössl, M.; Henry, T.D.; Lips, D.; et al. Prevalence, Trends, and Outcomes of Higher-Risk Percutaneous Coronary Interventions Among Patients without Acute Coronary Syndromes. Cardiovasc. Revasc. Med. 2019, 20, 289-292. [CrossRef]

161. Singh, M.; Lennon, R.J.; Gulati, R.; Holmes, D.R. Risk scores for 30-day mortality after percutaneous coronary intervention: New insights into causes and risk of death. Mayo Clin. Proc. 2014, 89, 631-637. [CrossRef] [PubMed]

162. Zack, C.J.; Senecal, C.; Kinar, Y.; Metzger, Y.; Bar-Sinai, Y.; Widmer, R.J.; Lennon, R.; Singh, M.; Bell, M.R.; Lerman, A.; et al. Leveraging Machine Learning Techniques to Forecast Patient Prognosis After Percutaneous Coronary Intervention. JACC Cardiovasc. Interv. 2019, 12, 1304-1311. [CrossRef] [PubMed]

163. Al'Aref, S.J.; Singh, G.; van Rosendael, A.R.; Kolli, K.K.; Ma, X.; Maliakal, G.; Pandey, M.; Lee, B.C.; Wang, J.; Xu, Z.; et al. Determinants of In-Hospital Mortality after Percutaneous Coronary Intervention: A Machine Learning Approach. J. Am. Heart Assoc. 2019, 8, e011160. [CrossRef] [PubMed]

164. Rao, S.V.; Kaul, P.R.; Liao, L.; Armstrong, P.W.; Ohman, E.M.; Granger, C.B.; Califf, R.M.; Harrington, R.A.; Eisenstein, E.L.; Mark, D.B. Association between bleeding, blood transfusion, and costs among patients with non-ST-segment elevation acute coronary syndromes. Am. Heart J. 2008, 155, 369-374. [CrossRef] [PubMed]

165. Kinnaird, T.D.; Stabile, E.; Mintz, G.S.; Lee, C.W.; Canos, D.A.; Gevorkian, N.; Pinnow, E.E.; Kent, K.M.; Pichard, A.D.; Satler, L.F.; et al. Incidence, predictors, and prognostic implications of bleeding and blood transfusion following percutaneous coronary interventions. Am. J. Cardiol. 2003, 92, 930-935. [CrossRef]

166. Rao, S.V.; McCoy, L.A.; Spertus, J.A.; Krone, R.J.; Singh, M.; Fitzgerald, S.; Peterson, E.D. An Updated Bleeding Model to Predict the Risk of Post-Procedure Bleeding Among Patients Undergoing Percutaneous Coronary Intervention: A Report Using an Expanded Bleeding Definition From the National Cardiovascular Data Registry CathPCI Registry. JACC Cardiovasc. Interv. 2013, 6, 897-904. [CrossRef]

167. Mortazavi, B.J.; Bucholz, E.M.; Desai, N.R.; Huang, C.; Curtis, J.P.; Masoudi, F.A.; Shaw, R.E.; Negahban, S.N.; Krumholz, H.M. Comparison of Machine Learning Methods With National Cardiovascular Data Registry Models for Prediction of Risk of Bleeding After Percutaneous Coronary Intervention. JAMA Netw. Open 2019, 2, e196835. [CrossRef]

168. Kim, M.S.; Dean, L.S. In-stent restenosis. Cardiovasc. Ther. 2011, 29, 190-198. [CrossRef]

169. Cassese, S.; Byrne, R.A.; Tada, T.; Pinieck, S.; Joner, M.; Ibrahim, T.; King, L.A.; Fusaro, M.; Laugwitz, K.L.; Kastrati, A. Incidence and predictors of restenosis after coronary stenting in 10004 patients with surveillance angiography. Heart 2014, 100, 153-159. [CrossRef]

170. Singh, M.; Gersh, B.J.; McClelland, R.L.; Ho, K.K.L.; Willerson, J.T.; Penny, W.F.; Holmes, D.R. Clinical and Angiographic Predictors of Restenosis After Percutaneous Coronary Intervention. Circulation 2004, 109, 2727-2731. [CrossRef]

171. Stolker, J.M.; Kennedy, K.F.; Lindsey, J.B.; Marso, S.P.; Pencina, M.J.; Cutlip, D.E.; Mauri, L.; Kleiman, N.S.; Cohen, D.J. Predicting Restenosis of Drug-Eluting Stents Placed in Real-World Clinical Practice. Circ. Cardiovasc. Interv. 2010, 3, 327-334. [CrossRef] [PubMed]

172. Sampedro-Gomez, J.; Dorado-Diaz, P.I.; Vicente-Palacios, V.; Sanchez-Puente, A.; Jimenez-Navarro, M.; San Roman, J.A.; Galindo-Villardon, P.; Sanchez, P.L.; Fernandez-Aviles, F. Machine Learning to Predict Stent Restenosis Based on Daily Demographic, Clinical, and Angiographic Characteristics. Can. J. Cardiol. 2020, 36, 1624-1632. [CrossRef] [PubMed] 
173. Steele, A.J.; Denaxas, S.C.; Shah, A.D.; Hemingway, H.; Luscombe, N.M. Machine learning models in electronic health records can outperform conventional survival models for predicting patient mortality in coronary artery disease. PLoS ONE 2018, 13, e0202344. [CrossRef]

174. Bertsimas, D.; Orfanoudaki, A.; Weiner, R.B. Personalized treatment for coronary artery disease patients: A machine learning approach. Health Care Manag. Sci. 2020, 23, 482-506. [CrossRef] [PubMed]

175. Farhadian, M.; Dehdar Karsidani, S.; Mozayanimonfared, A.; Mahjub, H. Risk factors associated with major adverse cardiac and cerebrovascular events following percutaneous coronary intervention: A 10-year follow-up comparing random survival forest and Cox proportional-hazards model. BMC Cardiovasc. Disord. 2021, 21, 38. [CrossRef]

176. Krittanawong, C.; Zhang, H.; Wang, Z.; Aydar, M.; Kitai, T. Artificial Intelligence in Precision Cardiovascular Medicine. J. Am. Coll. Cardiol. 2017, 69, 2657-2664. [CrossRef]

177. Taylor, A.J.; Bindeman, J.; Feuerstein, I.; Cao, F.; Brazaitis, M.; O’Malley, P.G. Coronary calcium independently predicts incident premature coronary heart disease over measured cardiovascular risk factors: Mean three-year outcomes in the Prospective Army Coronary Calcium (PACC) project. J. Am. Coll. Cardiol. 2005, 46, 807-814. [CrossRef]

178. Detrano, R.; Guerci, A.D.; Carr, J.J.; Bild, D.E.; Burke, G.; Folsom, A.R.; Liu, K.; Shea, S.; Szklo, M.; Bluemke, D.A.; et al. Coronary Calcium as a Predictor of Coronary Events in Four Racial or Ethnic Groups. N. Engl. J. Med. 2008, 358, 1336-1345. [CrossRef]

179. Rozanski, A.; Gransar, H.; Shaw, L.J.; Kim, J.; Miranda-Peats, L.; Wong, N.D.; Rana, J.S.; Orakzai, R.; Hayes, S.W.; Friedman, J.D.; et al. Impact of coronary artery calcium scanning on coronary risk factors and downstream testing the EISNER (Early Identification of Subclinical Atherosclerosis by Noninvasive Imaging Research) prospective randomized trial. J. Am. Coll. Cardiol. 2011, 57, 1622-1632. [CrossRef]

180. Hwang, I.-C.; Park, H.E.; Choi, S.-Y. Epicardial Adipose Tissue Contributes to the Development of Non-Calcified Coronary Plaque: A 5-Year Computed Tomography Follow-up Study. J. Atheroscler. Thromb. 2017, 24, 262-274. [CrossRef]

181. Nakanishi, R.; Rajani, R.; Cheng, V.Y.; Gransar, H.; Nakazato, R.; Shmilovich, H.; Otaki, Y.; Hayes, S.W.; Thomson, L.E.; Friedman, J.D.; et al. Increase in epicardial fat volume is associated with greater coronary artery calcification progression in subjects at intermediate risk by coronary calcium score: A serial study using non-contrast cardiac CT. Atherosclerosis 2011, 218, 363-368. [CrossRef] [PubMed]

182. Berman, D.S.; Arnson, Y.; Rozanski, A. Coronary Artery Calcium Scanning: The Agatston Score and Beyond. JACC Cardiovasc. Imaging 2016, 9, 1417-1419. [CrossRef] [PubMed]

183. Chao, H.; Shan, H.; Homayounieh, F.; Singh, R.; Khera, R.D.; Guo, H.; Su, T.; Wang, G.; Kalra, M.K.; Yan, P. Deep learning predicts cardiovascular disease risks from lung cancer screening low dose computed tomography. Nat. Commun. 2021, 12, 2963. [CrossRef] [PubMed]

184. Wolterink, J.; Leiner, T.; Takx, R.A.; Viergever, M.; Išgum, I. An Automatic Machine Learning System for Coronary Calcium Scoring in Clinical Non-Contrast Enhanced, ECG-Triggered Cardiac CT; SPIE: San Diego, CA, USA, 2014; Volume 9035.

185. Sandstedt, M.; Henriksson, L.; Janzon, M.; Nyberg, G.; Engvall, J.; De Geer, J.; Alfredsson, J.; Persson, A. Evaluation of an AI-based, automatic coronary artery calcium scoring software. Eur. Radiol. 2020, 30, 1671-1678. [CrossRef] [PubMed]

186. Commandeur, F.; Slomka, P.J.; Goeller, M.; Chen, X.; Cadet, S.; Razipour, A.; McElhinney, P.; Gransar, H.; Cantu, S.; Miller, R.J.H.; et al. Machine learning to predict the long-term risk of myocardial infarction and cardiac death based on clinical risk, coronary calcium, and epicardial adipose tissue: A prospective study. Cardiovasc. Res. 2020, 116, 2216-2225. [CrossRef]

187. Eisenberg, E.; McElhinney, P.A.; Commandeur, F.; Chen, X.; Cadet, S.; Goeller, M.; Razipour, A.; Gransar, H.; Cantu, S.; Miller, R.J.H.; et al. Deep Learning-Based Quantification of Epicardial Adipose Tissue Volume and Attenuation Predicts Major Adverse Cardiovascular Events in Asymptomatic Subjects. Circ. Cardiovasc. Imaging 2020, 13, e009829. [CrossRef]

188. Han, D.; Kolli, K.K.; Gransar, H.; Lee, J.H.; Choi, S.Y.; Chun, E.J.; Han, H.W.; Park, S.H.; Sung, J.; Jung, H.O.; et al. Machine learning based risk prediction model for asymptomatic individuals who underwent coronary artery calcium score: Comparison with traditional risk prediction approaches. J. Cardiovasc. Comput. Tomogr. 2020, 14, 168-176. [CrossRef]

189. Tamarappoo, B.K.; Lin, A.; Commandeur, F.; McElhinney, P.A.; Cadet, S.; Goeller, M.; Razipour, A.; Chen, X.; Gransar, H.; Cantu, S.; et al. Machine learning integration of circulating and imaging biomarkers for explainable patient-specific prediction of cardiac events: A prospective study. Atherosclerosis 2021, 318, 76-82. [CrossRef]

190. Nakanishi, R.; Slomka, P.J.; Rios, R.; Betancur, J.; Blaha, M.J.; Nasir, K.; Miedema, M.D.; Rumberger, J.A.; Gransar, H.; Shaw, L.J.; et al. Machine Learning Adds to Clinical and CAC Assessments in Predicting 10-Year CHD and CVD Deaths. JACC Cardiovasc. Imaging 2021, 14, 615-625. [CrossRef]

191. Min, J.K.; Feignoux, J.; Treutenaere, J.; Laperche, T.; Sablayrolles, J. The prognostic value of multidetector coronary CT angiography for the prediction of major adverse cardiovascular events: A multicenter observational cohort study. Int. J. Cardiovasc. Imaging 2010, 26, 721-728. [CrossRef]

192. Hadamitzky, M.; Achenbach, S.; Al-Mallah, M.; Berman, D.; Budoff, M.; Cademartiri, F.; Callister, T.; Chang, H.J.; Cheng, V.; Chinnaiyan, K.; et al. Optimized prognostic score for coronary computed tomographic angiography: Results from the CONFIRM registry (COronary CT Angiography EvaluatioN For Clinical Outcomes: An InteRnational Multicenter Registry). J. Am. Coll. Cardiol. 2013, 62, 468-476. [CrossRef] [PubMed]

193. Min, J.K.; Shaw, L.J.; Devereux, R.B.; Okin, P.M.; Weinsaft, J.W.; Russo, D.J.; Lippolis, N.J.; Berman, D.S.; Callister, T.Q. Prognostic Value of Multidetector Coronary Computed Tomographic Angiography for Prediction of All-Cause Mortality. J. Am. Coll. Cardiol. 2007, 50, 1161-1170. [CrossRef] [PubMed] 
194. Johnson, K.M.; Dowe, D.A. Prognostic Implications of Coronary CT Angiography: 12-Year Follow-Up of 6892 Patients. AJR Am. J. Roentgenol. 2020, 215, 818-827. [CrossRef] [PubMed]

195. Motwani, M.; Dey, D.; Berman, D.S.; Germano, G.; Achenbach, S.; Al-Mallah, M.H.; Andreini, D.; Budoff, M.J.; Cademartiri, F.; Callister, T.Q.; et al. Machine learning for prediction of all-cause mortality in patients with suspected coronary artery disease: A 5-year multicentre prospective registry analysis. Eur. Heart J. 2016, 38, 500-507. [CrossRef] [PubMed]

196. Tesche, C.; Bauer, M.J.; Baquet, M.; Hedels, B.; Straube, F.; Hartl, S.; Gray, H.N.; Jochheim, D.; Aschauer, T.; Rogowski, S.; et al. Improved long-term prognostic value of coronary $\mathrm{CT}$ angiography-derived plaque measures and clinical parameters on adverse cardiac outcome using machine learning. Eur. Radiol. 2021, 31, 486-493. [CrossRef]

197. van Rosendael, A.R.; Maliakal, G.; Kolli, K.K.; Beecy, A.; Al'Aref, S.J.; Dwivedi, A.; Singh, G.; Panday, M.; Kumar, A.; Ma, X.; et al. Maximization of the usage of coronary CTA derived plaque information using a machine learning based algorithm to improve risk stratification; insights from the CONFIRM registry. J. Cardiovasc. Comput. Tomogr. 2018, 12, 204-209. [CrossRef]

198. Hoshino, M.; Zhang, J.; Sugiyama, T.; Yang, S.; Kanaji, Y.; Hamaya, R.; Yamaguchi, M.; Hada, M.; Misawa, T.; Usui, E.; et al. Prognostic value of pericoronary inflammation and unsupervised machine-learning-defined phenotypic clustering of $\mathrm{CT}$ angiographic findings. Int. J. Cardiol. 2021, 333, 226-232. [CrossRef]

199. Johnson, K.M.; Johnson, H.E.; Zhao, Y.; Dowe, D.A.; Staib, L.H. Scoring of Coronary Artery Disease Characteristics on Coronary CT Angiograms by Using Machine Learning. Radiology 2019, 292, 354-362. [CrossRef]

200. Antonopoulos, A.S.; Sanna, F.; Sabharwal, N.; Thomas, S.; Oikonomou, E.K.; Herdman, L.; Margaritis, M.; Shirodaria, C.; Kampoli, A.M.; Akoumianakis, I.; et al. Detecting human coronary inflammation by imaging perivascular fat. Sci. Transl. Med. 2017, 9, eaal2658. [CrossRef]

201. Oikonomou, E.K.; Marwan, M.; Desai, M.Y.; Mancio, J.; Alashi, A.; Hutt Centeno, E.; Thomas, S.; Herdman, L.; Kotanidis, C.P.; Thomas, K.E.; et al. Non-invasive detection of coronary inflammation using computed tomography and prediction of residual cardiovascular risk (the CRISP CT study): A post-hoc analysis of prospective outcome data. Lancet 2018, 392, 929-939. [CrossRef]

202. Oikonomou Evangelos, K.; Desai Milind, Y.; Marwan, M.; Kotanidis Christos, P.; Antonopoulos Alexios, S.; Schottlander, D.; Channon Keith, M.; Neubauer, S.; Achenbach, S.; Antoniades, C. Perivascular Fat Attenuation Index Stratifies Cardiac Risk Associated with High-Risk Plaques in the CRISP-CT Study. J. Am. Coll. Cardiol. 2020, 76, 755-757. [CrossRef] [PubMed]

203. Oikonomou, E.K.; Williams, M.C.; Kotanidis, C.P.; Desai, M.Y.; Marwan, M.; Antonopoulos, A.S.; Thomas, K.E.; Thomas, S.; Akoumianakis, I.; Fan, L.M.; et al. A novel machine learning-derived radiotranscriptomic signature of perivascular fat improves cardiac risk prediction using coronary CT angiography. Eur. Heart J. 2019, 40, 3529-3543. [CrossRef] [PubMed]

204. Cabitza, F.; Rasoini, R.; Gensini, G.F. Unintended Consequences of Machine Learning in Medicine. JAMA 2017, 318, 517-518. [CrossRef] [PubMed]

205. Petch, J.; Di, S.; Nelson, W. Opening the black box: The promise and limitations of explainable machine learning in cardiology. Can. J. Cardiol. 2021. [CrossRef]

206. Lundberg, S.M.; Lee, S.-I. A unified approach to interpreting model predictions. In Proceedings of the 31st International Conference on Neural Information Processing Systems, Long Beach, CA, USA, 4-9 December 2017; pp. 4768-4777.

207. Vokinger, K.N.; Feuerriegel, S.; Kesselheim, A.S. Mitigating bias in machine learning for medicine. Commun. Med. $2021,1,25$. [CrossRef]

208. Tat, E.; Bhatt, D.L.; Rabbat, M.G. Addressing bias: Artificial intelligence in cardiovascular medicine. Lancet Digit Health 2020, 2 , e635-e636. [CrossRef]

209. Luo, Y. Evaluating the state of the art in missing data imputation for clinical data. Brief. Bioinform. 2021, 23, bbab489. [CrossRef]

210. Dietterich, T. Overfitting and undercomputing in machine learning. ACM Comput. Surv. (CSUR) 1995, 27, 326-327. [CrossRef]

211. Murdoch, B. Privacy and artificial intelligence: Challenges for protecting health information in a new era. BMC Med. Ethics 2021, 22, 122. [CrossRef] 